\title{
Prediction of enteric methane production, yield, and intensity in dairy cattle using an intercontinental database
}

\author{
Mutian Niu $^{1}$ | Ermias Kebreab ${ }^{1}$ (D) | Alexander N. Hristov ${ }^{2}$ | Joonpyo $\mathrm{Oh}^{2}$ | \\ Claudia Arndt $^{3}$ | André Bannink ${ }^{4}$ | Ali R. Bayat ${ }^{5}$ | André F. Brito ${ }^{6}$ | Tommy Boland ${ }^{7}$ | \\ David Casper $^{8}$ | Les A. Crompton ${ }^{9}$ | Jan Dijkstra ${ }^{10}$ | Maguy A. Eugène ${ }^{11}$ | \\ Phil C. Garnsworthy ${ }^{12}$ | Md Najmul Haque ${ }^{13}$ | Anne L. F. Hellwing ${ }^{14}$ |
}

Pekka Huhtanen $^{15}$ | Michael Kreuzer ${ }^{16}$ | Bjoern Kuhla ${ }^{17}$ | Peter Lund ${ }^{14}$ |

Jørgen Madsen ${ }^{13}$ | Cécile Martin ${ }^{11}$ | Shelby C. McClelland ${ }^{18}$ | Mark McGee ${ }^{19}$ | Peter

J. Moate ${ }^{20}$ | Stefan Muetzel ${ }^{21}$ | Camila Muñoz ${ }^{22}$ | Padraig O'Kiely ${ }^{19}$ | Nico Peiren ${ }^{23}$ |

Christopher K. Reynolds ${ }^{9}$ | Angela Schwarm ${ }^{16}$ | Kevin J. Shingfield ${ }^{24}$ |

Tonje M. Storlien ${ }^{25}$ | Martin R. Weisbjerg ${ }^{14}$ | David R. Yáñez-Ruiz ${ }^{26}$ | Zhongtang Yu ${ }^{27}$

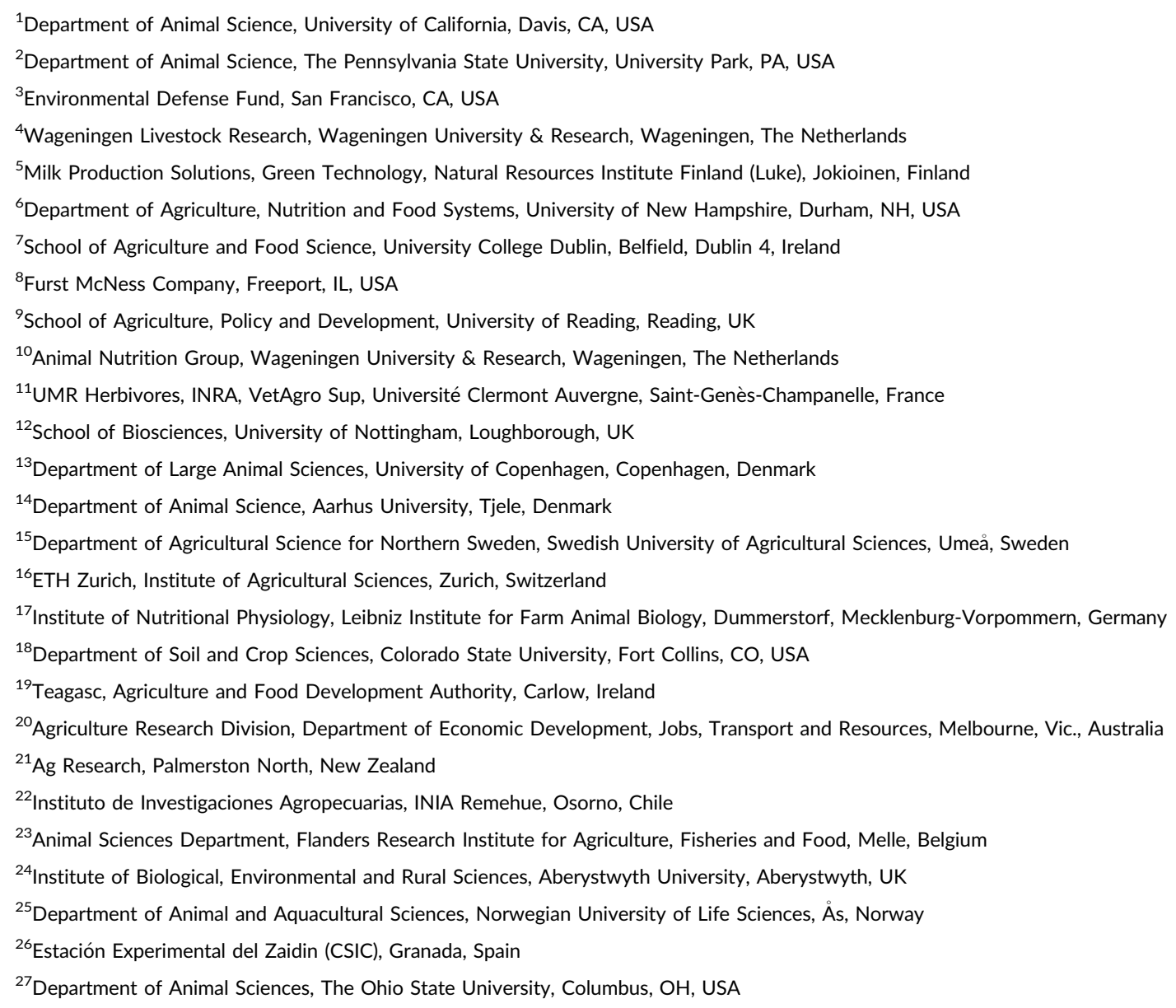




\section{Correspondence}

Ermias Kebreab, University of California, Davis, USA.

Email: ekebreab@ucdavis.edu

\section{Funding information}

FONDECYT, Grant/Award Number: 11110410, 1151355; Fontagro, Grant/ Award Number: FTG/RF-1028-RG; The Netherlands Ministry of Economic Affairs, Grant/Award Number: BO-20-007-006; Austin Eugene Lyons Fellowship; Academy of Finland, Grant/Award Number: 281337; USDA National Institute of Food and Agriculture, Grant/Award Number: 201467003-21979, NH00616-R; Department of Animal Science and College of Agricultural Sciences, Pennsylvania State University; the Dutch Dairy Board (Zoetermeer, The Netherlands); University of California, Davis Sesnon Endowed Chair Program; Pennsylvania Soybean Board; Agricultural GHG Research Initiative for Ireland; Northeast Sustainable Agriculture Research and Education; Swedish Infrastructure for Ecosystem Science (SITES) at Röbäcksdalen Research Station; Department for Environment, Food and Rural Affairs (Defra; UK); Defra, the Scottish Government, Department of Agriculture and Rural Development (Northern Ireland), and the Welsh Government as part of the UK's Agricultural GHG Research Platform projects; Swiss Federal Office of Agriculture, Berne, Switzerland; French National Research Agency, Grant/Award Number: ANR-13-JFAC-0003-01; New Hampshire Agricultural Experiment Station; the Product Board Animal Feed (Zoetermeer, The Netherlands); PMI Nutritional Additives; DSM Nutritional Products; German Federal Ministry of Food and Agriculture (BMBL) through the Federal Office for Agriculture and Food (BLE); European Commission through SMEthane, Grant/Award Number: FP7-SME-262270; INIA, Spain, Grant/Award Number: MIT01-GLOBALNET-EEZ

\section{Abstract}

Enteric methane $\left(\mathrm{CH}_{4}\right)$ production from cattle contributes to global greenhouse gas emissions. Measurement of enteric $\mathrm{CH}_{4}$ is complex, expensive, and impractical at large scales; therefore, models are commonly used to predict $\mathrm{CH}_{4}$ production. However, building robust prediction models requires extensive data from animals under different management systems worldwide. The objectives of this study were to (1) collate a global database of enteric $\mathrm{CH}_{4}$ production from individual lactating dairy cattle; (2) determine the availability of key variables for predicting enteric $\mathrm{CH}_{4}$ production ( $\mathrm{g} /$ day per cow), yield $[\mathrm{g} / \mathrm{kg}$ dry matter intake (DMI)], and intensity $(\mathrm{g} / \mathrm{kg}$ energy corrected milk) and their respective relationships; (3) develop intercontinental and regional models and cross-validate their performance; and (4) assess the trade-off between availability of on-farm inputs and $\mathrm{CH}_{4}$ prediction accuracy. The intercontinental database covered Europe (EU), the United States (US), and Australia (AU). A sequential approach was taken by incrementally adding key variables to develop models with increasing complexity. Methane emissions were predicted by fitting linear mixed models. Within model categories, an intercontinental model with the most available independent variables performed best with root mean square prediction error (RMSPE) as a percentage of mean observed value of $16.6 \%, 14.7 \%$, and $19.8 \%$ for intercontinental, EU, and United States regions, respectively. Less complex models requiring only DMI had predictive ability comparable to complex models. Enteric $\mathrm{CH}_{4}$ production, yield, and intensity prediction models developed on an intercontinental basis had similar performance across regions, however, intercepts and slopes were different with implications for prediction. Revised $\mathrm{CH}_{4}$ emission conversion factors for specific regions are required to improve $\mathrm{CH}_{4}$ production estimates in national inventories. In conclusion, information on DMI is required for good prediction, and other factors such as dietary neutral detergent fiber (NDF) concentration, improve the prediction. For enteric $\mathrm{CH}_{4}$ yield and intensity prediction, information on milk yield and composition is required for better estimation.

\section{KEYWORDS}

dairy cows, dry matter intake, enteric methane emissions, methane intensity, methane yield, prediction models

\section{1 | INTRODUCTION}

Emissions of greenhouse gases (GHG) have a considerable impact on climate change, which is an ongoing threat for global food security. Global food demand in the next 30 years is projected to increase by over $60 \%$ compared to 2006 , with more than 321 million people worldwide at risk of hunger without implementation of climate change mitigation policies (FAO, 2016). The GHG emissions from livestock are estimated to be $7.1 \mathrm{Gt}$ carbon dioxide $\left(\mathrm{CO}_{2}\right)$ equivalents per year accounting for $14.5 \%$ of global anthropogenic GHG emissions (Gerber et al., 2013). Methane $\left(\mathrm{CH}_{4}\right)$ is emitted from livestock mainly through enteric fermentation and manure decomposition. Enteric $\mathrm{CH}_{4}$ is a natural by-product of microbial fermentation of nutrients in the digestive tract of animals. Globally, most attention has been directed to enteric $\mathrm{CH}_{4}$ emissions from ruminants, particularly cattle because these farm species have been shown to be the major contributors of total GHG emissions from the livestock sector (Gerber et al., 2013; Tubiello et al., 2013).

Attempts to reduce the carbon footprint of animal agriculture systems, primarily on-farm GHG emissions, will ideally involve implementation of mitigation strategies without compromising animal productivity or social acceptability, and without endangering animal health or welfare. To reduce the impact on the environment, the amount of $\mathrm{CH}_{4}$ produced within a production system needs to be 
quantified accurately so that emission can be mitigated through management. Direct measurement of enteric $\mathrm{CH}_{4}$ production from cattle can be conducted using various techniques including several bottom-up and some top-down approaches, i.e., based on national or regional activity data and emission factors for different $\mathrm{CH}_{4}$ sources, or on atmospheric measurements, respectively. However, measurements of $\mathrm{CH}_{4}$ production from individual animals, groups of animals, or at a regional level is expensive and requires specialized equipment (Hammond et al., 2016; Kebreab, Clark, Wagner-Riddle, \& France, 2006). Proxies (i.e., indicators or indirect traits) for $\mathrm{CH}_{4}$ emissions have also been qualitatively explored, but no single proxy was found to accurately predict $\mathrm{CH}_{4}$ and combinations of proxies to date are not sufficiently robust for general applicability (Negussie et al., 2017). Therefore, quantitative approaches such as mathematical modeling have been used to estimate $\mathrm{CH}_{4}$ production in cattle (Kebreab, Johnson, Archibeque, Pape, \& Wirth, 2008). Both mechanistic and empirical approaches have been used to predict enteric $\mathrm{CH}_{4}$ emissions. However, mechanistic models are usually more detailed and require numerous inputs that may not be readily available; therefore, their utility in practice is reduced. An empirical prediction approach requires fewer inputs and can generally be implemented by a much wider audience including scientists and policy makers. There are over 40 empirical prediction equations for enteric $\mathrm{CH}_{4}$ production of lactating dairy cows in the literature (Appuhamy, France, \& Kebreab, 2016). The majority of these models were based on measurements from relatively small numbers of animals in the same geographic region, which may limit their application in other regions. Therefore, a more comprehensive database needs to be collated to develop enteric $\mathrm{CH}_{4}$ production prediction models at both global and regional scales. Furthermore, the performance of global models in each geographic region should be evaluated and compared with regional-specific prediction models.

The $\mathrm{CH}_{4}$ conversion factor $\left(\mathrm{Y}_{\mathrm{m}}\right)$ was introduced by the Intergovernmental Panel on Climate Change (IPCC) to indicate the proportion of the animal's gross energy intake (GEI) converted to enteric $\mathrm{CH}_{4}$ energy, and it is widely used for national GHG emission inventories and global research on mitigation strategies. However, it has been consistently shown that $\mathrm{CH}_{4}$ emissions are related not only to feed intake but also to feed nutrient compositions, which $Y_{\mathrm{m}}$-based models cannot adequately represent (Ellis, Bannink, France, Kebreab, \& Dijkstra, 2010). Therefore, identifying relationships between dietary variables and $\mathrm{CH}_{4}$ production and their impacts on prediction and model performance are critical. Several extant prediction models require inputs that may not be commonly available in a commercial dairy production system. Although predictive ability is likely to be enhanced with model complexity (Moraes, Strathe, Fadel, Casper, \& Kebreab, 2014; Santiago-Juarez et al., 2016), the trade-off between availability of variable inputs on farm and prediction accuracy of enteric $\mathrm{CH}_{4}$ production of dairy cows must be carefully considered. This is because more complex models may contain predictor variables that are expensive and not easy to obtain and thereby not applicable, especially in developing countries. Therefore, a categorization of model types which reflect different types and levels of data availability (e.g., diet composition, milk production and composition, and animal characteristics) needs to be conducted. Evaluation of model performance across various categories can be useful for different groups (e.g., researchers, regulators etc.).

The objectives of this study were to: (1) collate a global database of enteric $\mathrm{CH}_{4}$ production in individual lactating dairy cows; (2) determine the availability of key variables for predicting enteric $\mathrm{CH}_{4}$ production (g/day per cow), yield [g/kg dry matter intake (DMI)], and intensity $[\mathrm{g} / \mathrm{kg}$ energy corrected milk (ECM)] and their respective relationships; (3) develop intercontinental and regional-specific prediction equations for $\mathrm{CH}_{4}$ production, yield, and intensity using a large individual cow database and cross-validate their performance; and (4) assess the trade-off between the availability of on-farm variable inputs and prediction accuracy of enteric $\mathrm{CH}_{4}$ production, yield, and intensity in lactating dairy cows.

\section{MATERIALS AND METHODS}

\subsection{Database}

The "GLOBAL NETWORK" project (Global Network for the Development and Maintenance of Nutrition-Related Strategies for Mitigation of Methane and Nitrous Oxide Emissions from Ruminant Livestock; 2014-2018) is an international collaborative initiative of animal scientists from all continents, except Africa (http://animalscience.psu.ed $\mathrm{u} / \mathrm{fnn}$; accessed May 16, 2017). The dairy $\mathrm{CH}_{4}$ database, developed in the frame of the "GLOBAL NETWORK" project, contains 5,233 individual dairy cow records from 154 published and unpublished studies conducted from 1962 to 2016 by researchers and research institutes from 15 countries in Europe (EU; $n=3,015$ from 82 studies), the United States of America (US; $n=1,916$ from 64 studies), Chile (CL; $n=108$ from 3 studies), Australia (AU; $n=64$ from 1 study), and New Zealand (NZ; $n=130$ from 4 studies). The database includes records of enteric $\mathrm{CH}_{4}$ production along with corresponding DMI, dietary concentration of gross energy (GE), crude protein (CP), ether extract (EE), neutral detergent fiber (NDF), and ash. It also includes milk yield (MY), concentrations of milk fat (MF) and crude protein (MP), and body weight (BW) records. The EU studies were conducted in the United Kingdom ( $n=930$ from 38 studies), Denmark ( $n=512$ from 12 studies), Switzerland ( $n=483$ from 9 studies), Sweden ( $n=357$ from 5 studies), the Netherlands ( $n=188$ from 5 studies), Finland ( $n=170$ from 2 studies), Belgium ( $n=104$ from 4 studies), Ireland ( $n=90$ from 1 study), Norway ( $n=88$ from 4 studies), Germany ( $n=61$ from 1 study), and France ( $n=32$ from 1 study).

Energy corrected milk ( $3.5 \%$ fat) was calculated based on an equation derived from Tyrrell and Reid (1965): ECM (kg/day) $=12.95 \times$ fat yield $(\mathrm{kg} /$ day $)+7.65 \times$ true protein yield $(\mathrm{kg} /$ day; i.e., crude protein $\times 0.93)+0.327 \times$ milk yield ( $\mathrm{kg} /$ day). The majority of studies had measured GE. If the feed ingredients and proportions in the diets were known, the GE was calculated from book values (about 6\%). Methane yield $\left(\mathrm{CH}_{4}\right.$ production divide by DMI) and intensity $\left(\mathrm{CH}_{4}\right.$ production divide by ECM) were calculated for all records. 
The majority of the studies in the database had investigated the impact of diet composition on enteric $\mathrm{CH}_{4}$ production. However, about $20 \%$ of the studies tested the effect of feed additives or pure nutrient supplementation, so data from these studies were either completely excluded or only the control treatments were retained. These feed additives included nitrate (Olijhoek et al., 2016), 3nitrooxypropanol (Hristov et al., 2015), and intragastric infusion of acetate, propionate, glucose, and cis- or trans-fatty acids. Measurements of enteric $\mathrm{CH}_{4}$ production were conducted using various approaches although the observations from a given research group were usually measured using the same approach. To ensure data quality, only enteric $\mathrm{CH}_{4}$ measurements from respiration chambers, the GreenFeed system (C-Lock Inc., Rapid City, SD), and sulfur hexafluoride $\left(\mathrm{SF}_{6}\right)$ tracer technique were retained for the analysis.

The variable selection and model evaluation approaches required complete data for all predictor and response variables. Therefore, records missing any predictor or response variable information were removed before being screened for outliers. Outliers in the database were screened using the interquartile range (IQR) method (Zwillinger \& Kokoska, 2000) based on $\mathrm{CH}_{4}$ yield and intensity records for each region. In this study, a factor of 1.5 for extremes was used in constructing markers to identify outliers, as shown in the Equations (i-iii):

$$
\begin{gathered}
\mathrm{IQR}=\text { Third Quartile (Q3) }- \text { First Quartile (Q1); } \\
\text { Lower Fence }=\mathrm{Q} 1-(\mathrm{IQR} \times 1.5) ; \\
\text { Upper Fence }=\mathrm{Q} 3+(\mathrm{IQR} \times 1.5) .
\end{gathered}
$$

As a result, a refined complete data set $(n=2,566)$, containing complete information on $\mathrm{CH}_{4}$ production, $\mathrm{DMI}, \mathrm{GEI}$, dietary concentrations of GE, CP, EE, NDF, and ash, MY, MF, MP, ECM, and BW were used for variable selection and comparison of prediction model performance for lactating dairy cows as described below. Summary statistics for EU, the United States, and intercontinental records (combination of EU, US, and AU data) are shown in Table 1. Overall, the data set comprised individual observations from Holstein (68\%; $n=1,732$ ), Ayrshire (19\%; $n=497$ ), Jersey (3\%; $n=88$ ), as well as Brown Swiss, Simmental, and crossbred dairy cattle (a total of $10 \% ; n=249$ ). The breakdown of observations in the complete intercontinental data set was 1,423 from EU (42 studies), 1,084 from the United States (45 studies), and 59

\begin{tabular}{|c|c|c|c|c|c|c|c|c|c|c|c|c|}
\hline \multirow[b]{2}{*}{ Item $^{a}$} & \multicolumn{4}{|c|}{ Intercontinental $^{\mathrm{b}}(n=2,566)$} & \multicolumn{4}{|c|}{$\mathrm{EU}(n=1,423)$} & \multicolumn{4}{|c|}{ US $(n=1,084)$} \\
\hline & Mean & $\operatorname{Min}^{c}$ & Max & $S D$ & Mean & Min & Max & SD & Mean & Min & Max & $S D$ \\
\hline DMI (kg/day) & 18.5 & 3.9 & 35.4 & 4.60 & 18.5 & 8.0 & 33.5 & 3.84 & 18.8 & 3.9 & 35.4 & 5.48 \\
\hline \multicolumn{13}{|c|}{ Diet composition (\% of DM) } \\
\hline $\mathrm{CP}$ & 16.5 & 8.1 & 25.3 & 2.43 & 16.5 & 8.1 & 25.3 & 2.58 & 16.5 & 9.8 & 23.5 & 2.18 \\
\hline ash & 7.3 & 3.4 & 19.5 & 1.76 & 7.9 & 3.7 & 19.5 & 1.89 & 6.4 & 3.4 & 12.1 & 1.07 \\
\hline NDF & 35.4 & 13.4 & 70.0 & 7.66 & 36.6 & 13.4 & 57.0 & 7.83 & 33.3 & 14.9 & 70.0 & 6.77 \\
\hline GE (MJ/kg DM) & 18.7 & 16.1 & 22.8 & 0.69 & 18.6 & 16.1 & 22.8 & 0.75 & 18.8 & 17.3 & 20.7 & 0.56 \\
\hline \multicolumn{13}{|l|}{ Yield } \\
\hline MY, kg/day & 27.0 & 4.3 & 62.7 & 9.76 & 26.4 & 7.6 & 51.4 & 7.92 & 28.4 & 4.3 & 62.7 & 11.50 \\
\hline MP & 3.4 & 2.3 & 5.3 & 0.38 & 3.4 & 2.3 & 4.9 & 0.37 & 3.2 & 2.3 & 5.3 & 0.35 \\
\hline BW (kg) & 611 & 283 & 939 & 88.1 & 614 & 283 & 939 & 89.3 & 611 & 302 & 854 & 86.4 \\
\hline \multicolumn{13}{|l|}{ Methane emissions } \\
\hline $\mathrm{CH}_{4}$ (g/day per cow) & 369 & 79 & 729 & 100.7 & 392 & 169 & 701 & 88.8 & 340 & 79 & 729 & 109.3 \\
\hline $\mathrm{CH}_{4} / \mathrm{DMI}(\mathrm{g} / \mathrm{kg})$ & 20.1 & 9.0 & 30.4 & 3.87 & 21.4 & 12.3 & 30.4 & 3.39 & 18.2 & 9.0 & 28.0 & 3.71 \\
\hline $\mathrm{CH}_{4} / \mathrm{ECM}(\mathrm{g} / \mathrm{kg})$ & 13.5 & 3.0 & 36.0 & 3.92 & 13.6 & 5.1 & 22.3 & 3.07 & 12.8 & 3.0 & 24.8 & 4.25 \\
\hline$Y_{m}{ }^{d}(\%$ of GEI) & 6.0 & 2.7 & 9.8 & 1.18 & 6.4 & 3.6 & 9.8 & 1.04 & 5.4 & 2.7 & 8.4 & 1.09 \\
\hline
\end{tabular}
from AU ( 1 study). Ninety-one percent of the US observations were

TABLE 1 Summary statistics of the refined complete data set in different regions

${ }^{a} \mathrm{DM}$, dry matter; DMI, dry matter intake; GEI, gross energy intake; CP, dietary crude protein concentration; EE, dietary ether extract concentration; ash, dietary ash concentration; NDF, dietary neutral detergent fiber concentration; MY, milk yield; ECM, energy corrected milk; MF, milk fat concentration; MP, milk crude protein concentration; BW, body weight.

${ }^{\mathrm{b}} \mathrm{EU}$, Europe; US, the United States of America; $A U$, Australia; Intercontinental $=(E U+U S+A U)$.

${ }^{\mathrm{c}}$ Min, minimum; Max, maximum; SD, standard deviation.

${ }^{\mathrm{d}}$ Methane conversion factor (\%) $=$ energy of $\mathrm{CH}_{4}$ as a percentage of GEl. 
from Holstein cows, while the remaining were Jersey. Holstein, Ayrshire, Jersey, and other breeds provided $44,35,3$, and $18 \%$ of EU data, respectively, and $\mathrm{AU}$ data were from Holstein cows.

Unlike variable selection and model evaluation approaches, the construction of equations does not require data that contain a complete set of all predictor variables. Therefore, to be able to maximize the amount of data useful to construct prediction equations, subsets of data that contain complete information of $\mathrm{CH}_{4}$ production and of the selected corresponding predictor variables were screened for outliers using the IQR method stated above and then used for the construction of equations. The same approaches were done for $\mathrm{CH}_{4}$ yield and intensity models.

\section{2 | Model development}

Model development was conducted using a sequential approach, by incrementally adding different levels (e.g., dietary composition, milk production and composition, and animal traits) of variables to develop models with increasing complexity. In total, $11 \mathrm{CH}_{4}$ production prediction models with different complexity categories were developed (Table 2) using the following information: GEI only (GEI_C), DMI only (DMI_C), DMI and dietary NDF concentration (DMI + NDF_C), DMI and dietary $\mathrm{EE}$ concentration (DMI + EE_C), DMI and all dietary composition (DMI + Com_C), all available dietary composition only (Diet_Com_C), MY only (MY_C), ECM only (ECM_C), ECM and milk composition (ECM + Com_C), all the available variables (Animal_C), and all available variables except DMI (Animal_no_DMI_C). Within each category, both intercontinental and regional models were developed; however, regional models were for EU and United States only due to the limited number of observations from other regions (Tables 3 and 4). Seven $\mathrm{CH}_{4}$ yield models with different complexity levels were developed (Table 5) without predictors associated with DMI (Table 5). The categories were: dietary NDF concentration (NDF_C), dietary EE concentration (EE_C), Diet_Com_C, MY_C ECM_C, ECM + Com_C, and Animal_no_DMI_C. Similarly, $9 \mathrm{CH}_{4}$ intensity models with different complexity levels were developed (Table 6) without using either MY or ECM: GEI_C, DMI_C, DMI + NDF_C, DMI + EE_C, DMI + Com_C, Diet_Com_C, milk composition only (Milk_Com_C), all the available variables except MY and ECM (Animal_C), and all available variables except DMI, MY, and ECM (Animal_no_DMI_C) (Table 6). As described above, the refined complete data set $(n=2,566)$ that contains all predictor variables was used for model selection and evaluation, and the final equation was constructed based on a complete data set that only contained the selected predictor variables of the corresponding model for each category. Therefore, the amount of data was maximized for the development of equations at different complexity levels.

Methane production was predicted by fitting a mixed effect model using the Imer (Bates, Maechler, Bolker, \& Walker, 2015) procedure of $R$ statistical language ( $R$ Core Team 2016; version 3.3.0). The model was developed as shown in Equation (iv):

$$
Y=\beta_{0}+\beta_{1} X_{1}+\beta_{2} X_{2}+\cdots+\beta_{n} X_{n}+S_{i}\left(R_{j}\right)+R_{j}+\epsilon,
$$

where $\mathrm{Y}$ denotes the response variable of $\mathrm{CH}_{4}$ production $(\mathrm{g} /$ day per cow), $\mathrm{CH}_{4}$ yield (g/kg DMI) or $\mathrm{CH}_{4}$ intensity (g/kg ECM); $\beta_{0}$ denotes the fixed effect of intercept; $X_{1}$ to $X_{n}$ denote the fixed effects of predictor variables and $\beta_{1}$ to $\beta_{n}$ are the corresponding slopes; $S_{i}\left(R_{j}\right)$ denotes the random study effects nested in research group; $R_{j}$ denotes the random research group effects (research groups that contributed data for analysis were used to capture variations such as different regional weather conditions, $\mathrm{CH}_{4}$ measurement methods used, research protocols etc.); $\varepsilon$ denotes the within-experiment error. Explanatory variables, which play a key role in predicting $\mathrm{CH}_{4}$ production were selected for $\mathrm{DMI}+\mathrm{Com}_{-} \mathrm{C}$, Diet_Com_C, ECM + Com_C, Animal_C, and Animal_no_DMI_C using a comprehensive selection approach as follows: all of the subset models were fitted to the complete data set (total of 2,566 observations) and the corresponding Bayesian information criterion (BIC) scores were computed. The BIC was calculated as: $n \log \frac{\mathrm{SSE}_{p}}{n}+(\log n) p$, where $p$ is the number of regression coefficients, $n$ is the sample size, and $\mathrm{SSE}_{p}$ is error sum of squares. A model with a smaller BIC is preferred because it reaches a balance between the goodness of fit and model complexity. In addition, the presence of multicollinearity of fitted models was examined conservatively based on variance inflation factor (VIF). A VIF in excess of 5 was considered an indicator of multicollinearity (Kutner et al., 2005), and identified predictor variables with the largest VIF were removed from the model one at a time. Similar variable selection procedures as described above were adopted for $\mathrm{CH}_{4}$ yield (for Diet_Com_C, ECM + Com_C, and Animal_no_DMI_C) and $\mathrm{CH}_{4}$ intensity (for DMI + Com_C, Diet_Com_C, Milk_Com_C, Animal_C, and Animal_no_DMI_C).

\section{3 | Cross-validation and model evaluation}

The predictive accuracy of fitted $\mathrm{CH}_{4}$ prediction models at different categories was evaluated using the revised k-fold cross-validation method (James, Witten, Hastie, \& Tibshirani, 2014), based on the refined complete data set (total of 2,566 observations), with folds composed of individual study ( $k=$ number of studies). Each individual fold was treated as a validation set. The prediction of $\mathrm{CH}_{4}$ production of each fold was computed using the model that was fitted from the remaining folds as described by Moraes et al. (2014). The predictions of all folds were used to conduct model evaluation metrics as described below. Evaluation of all models developed at each category was assessed on intercontinental, EU, and US complete data sets.

A combination of model evaluation metrics was used to assess model performance including mean square prediction error (MSPE), root MSPE (RMSPE), mean absolute error (MAE), and concordance correlation coefficient (CCC). The MSPE was calculated according to Bibby and Toutenburg (1977) as shown in Equation (v): 


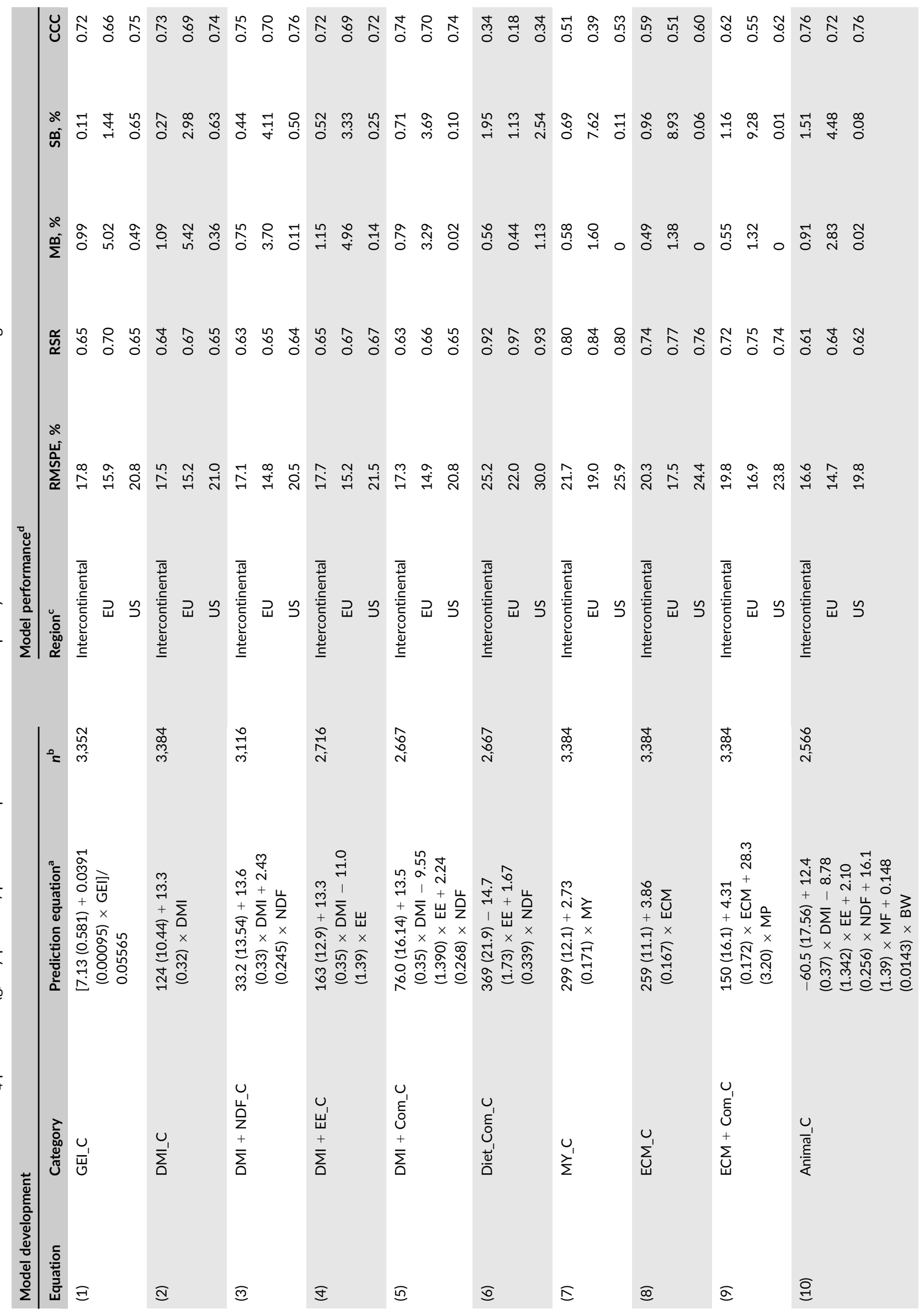




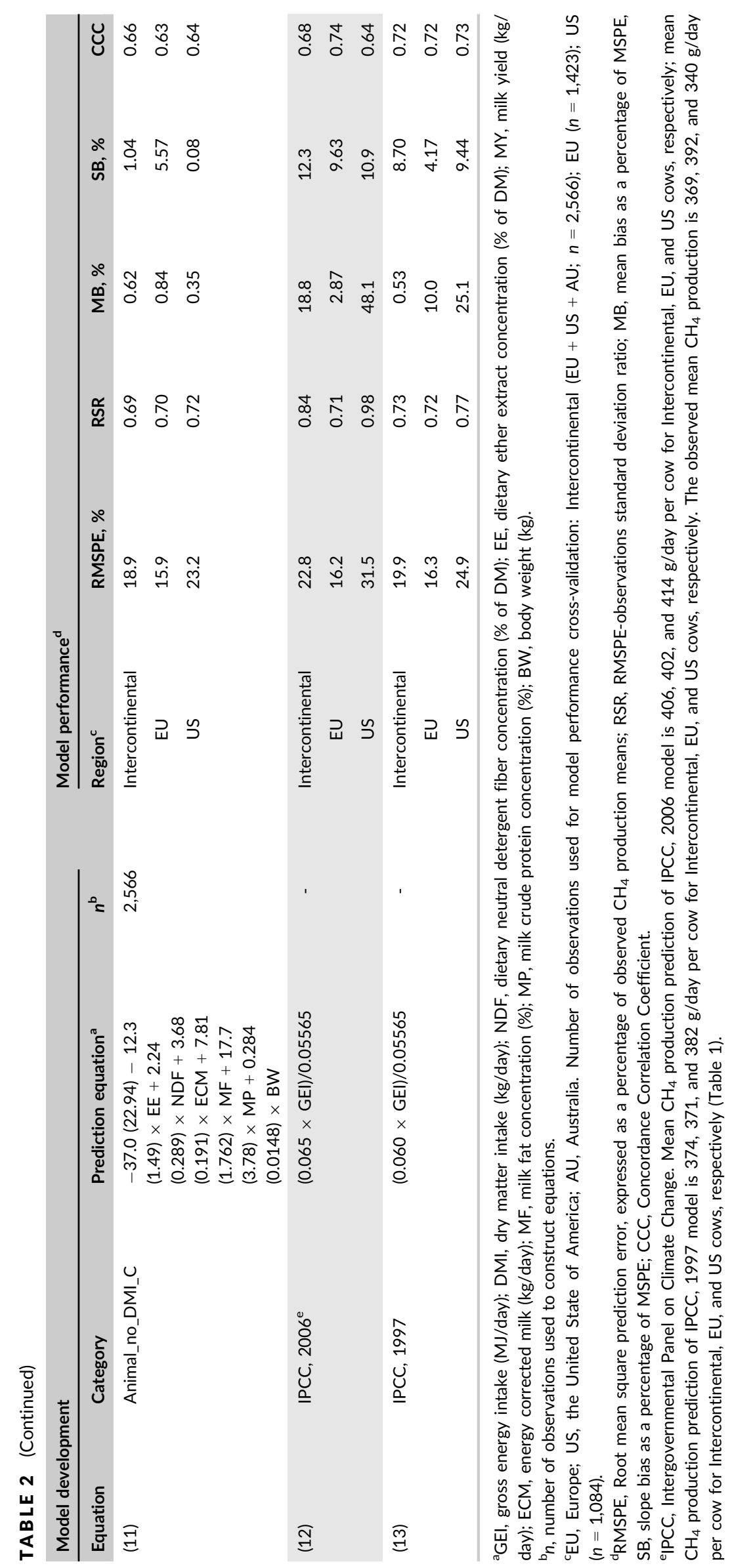




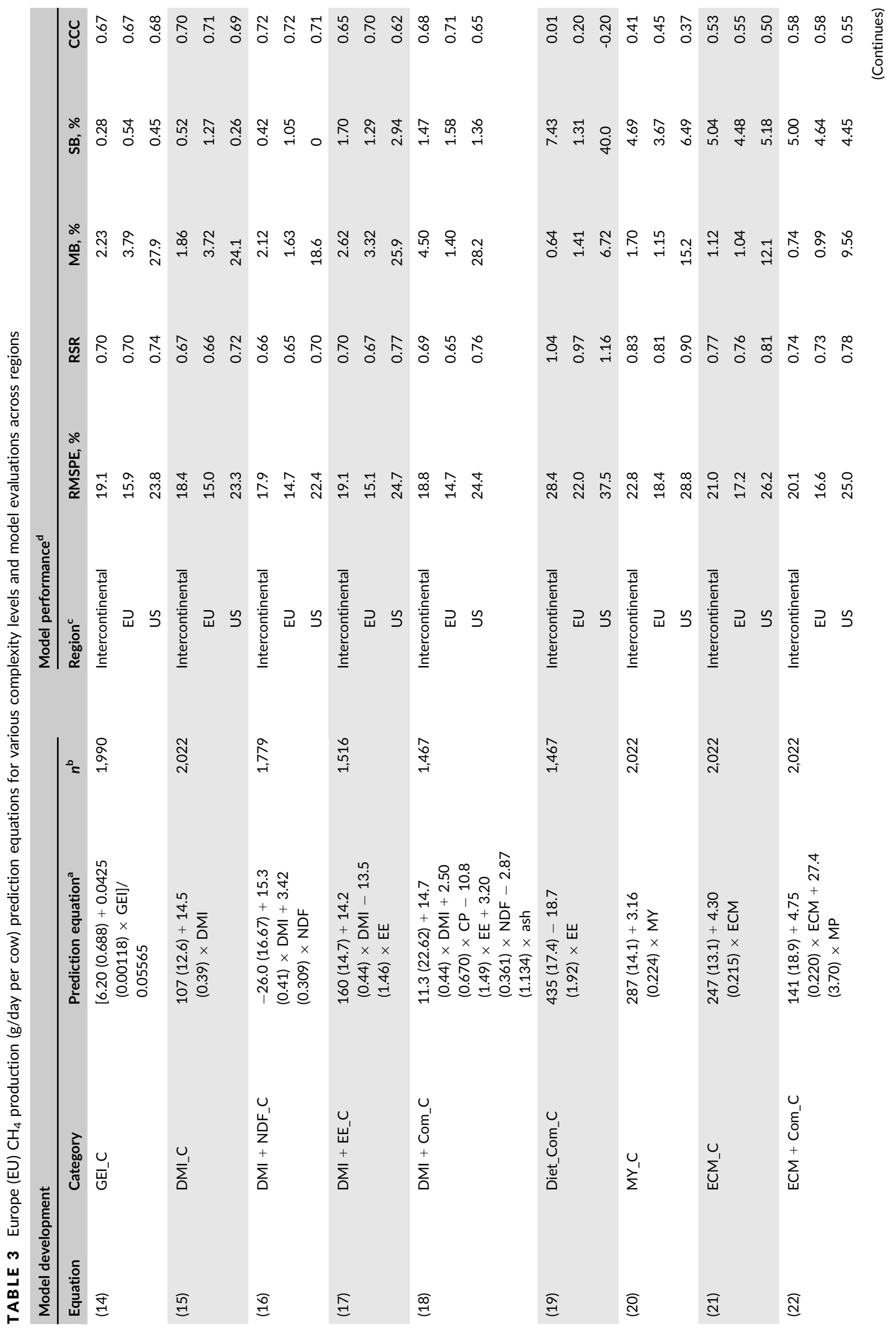




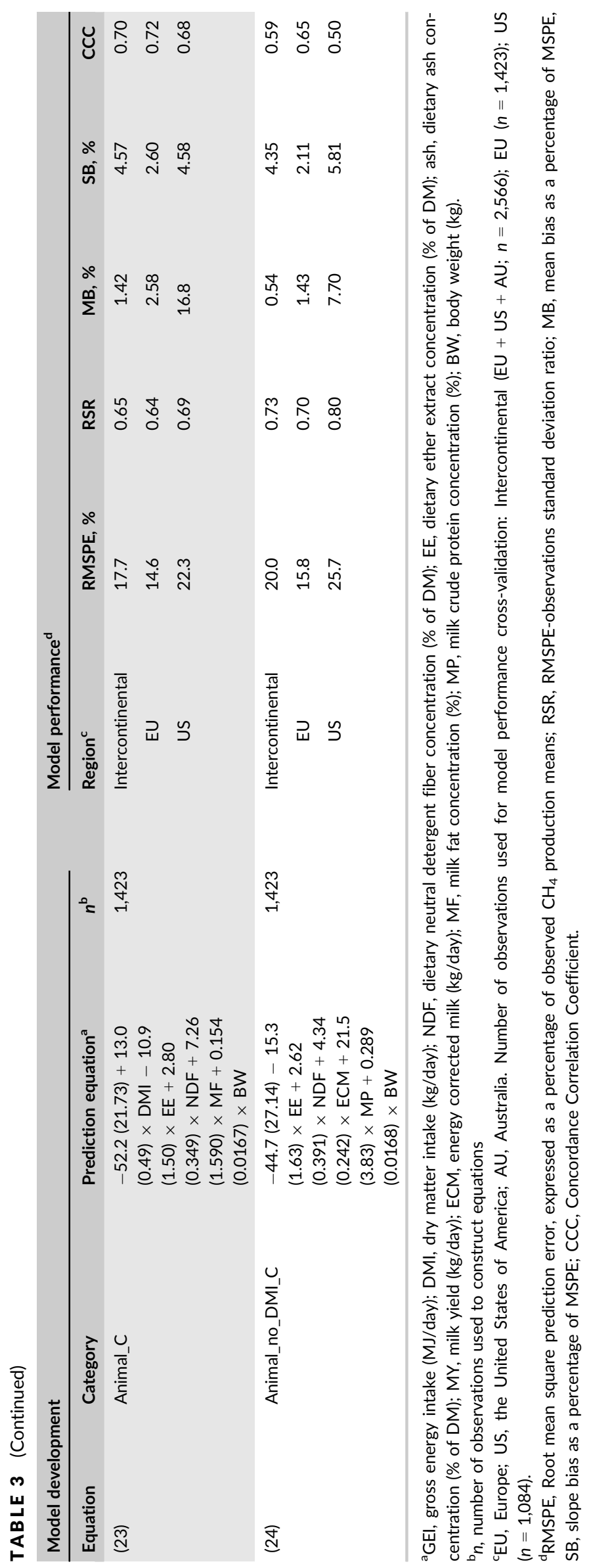




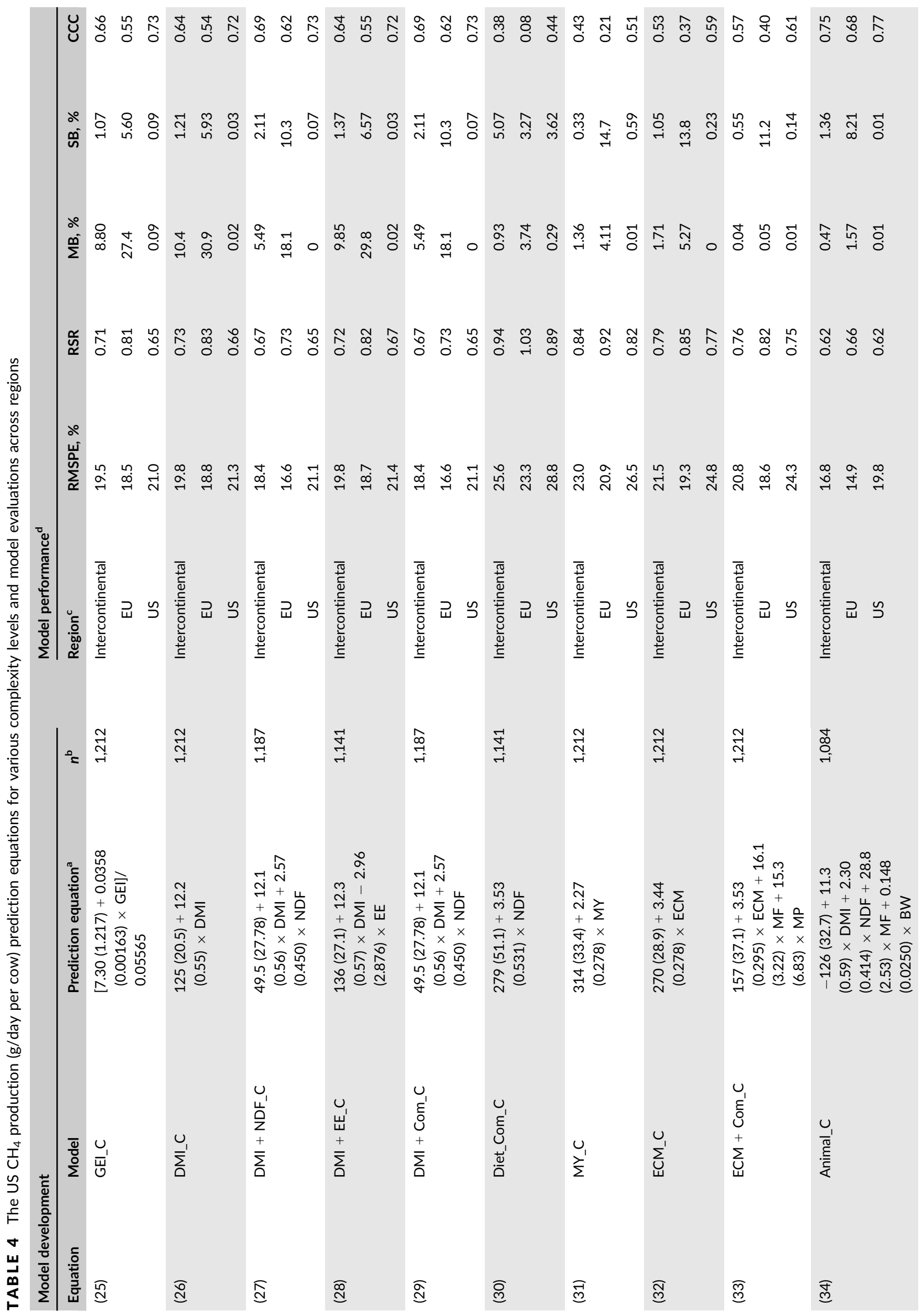




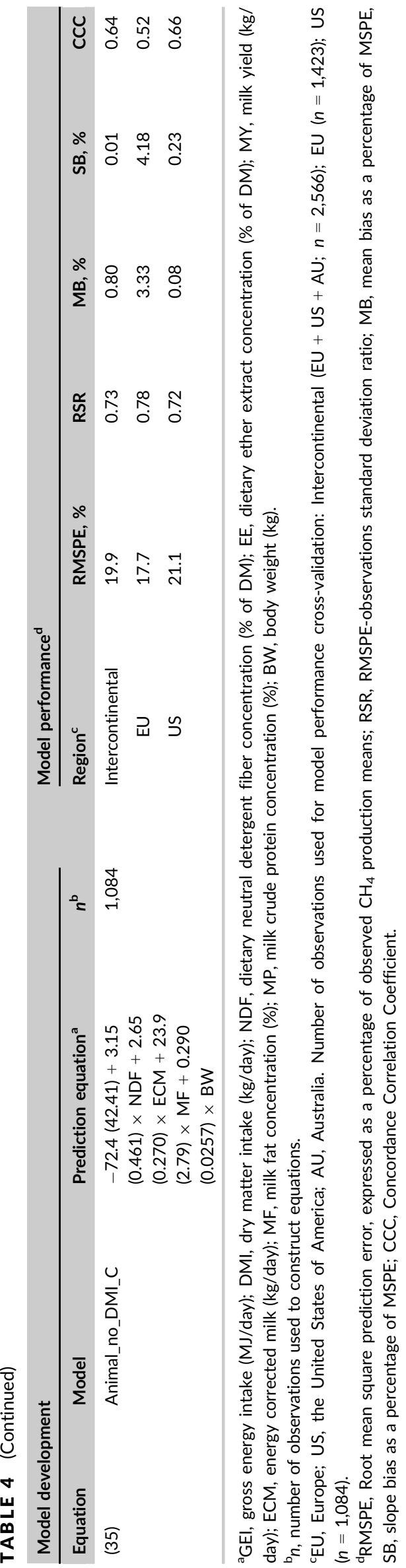

$$
\text { MSPE }=\frac{\sum_{i=1}^{n}\left(Y_{i}-\hat{Y}_{i}\right)^{2}}{n}
$$

where $Y_{i}$ denotes the observed value of the response variable for the $i$ th observation, $\hat{Y}_{i}$ denotes the predicted value of the response variable for the ith observation, $n$ denotes the number of observations. The RMSPE was used to assess overall model prediction accuracy because its output was in the same unit as the observations. In this study, RMSPE was reported as a proportion of observed $\mathrm{CH}_{4}$ production means in order to compare the predictive capability of models developed from different data sets. The MAE was calculated as shown in Equation (vi) to quantify the prediction error as suggested by Chai and Draxler (2014):

$$
\mathrm{MAE}=\frac{\sum_{i=1}^{n}\left|Y_{i}-\hat{Y}_{i}\right|}{n}
$$

In both cases, smaller RMSPE or MAE implies better model performance. The RMSPE to standard deviation of observed values ratio (RSR) was calculated as shown in Equation (vii),

$$
\mathrm{RSR}=\frac{\mathrm{RMSPE}}{S_{0}}
$$

where $S_{0}$ denotes the standard deviation of observations. It was used to compare the performance of a single model based on data from different regions accounting for the regional variability (Moriasi et al., 2007). Similarly, smaller RSR indicates better model predictive ability given the variability of data. MSPE was decomposed into mean bias (MB) and slope bias (SB) deviations to identify systematic biases. The MB and SB were calculated as shown in Equations (viii) and (ix), respectively:

$$
\begin{gathered}
\mathrm{MB}=(\bar{P}-\bar{O})^{2} \\
\mathrm{SB}=\left(S_{p}-r \times S_{0}\right)^{2}
\end{gathered}
$$

where $\bar{P}$ and $\bar{O}$ denote the predicted and observed means, $S_{p}$ denotes the standard deviation of predicted values, and $r$ denotes the Pearson correlation coefficient.

Furthermore, CCC was conducted that includes a bias correction factor $\left(C_{b}\right)$ and $r$, as measurements of accuracy and precision, respectively (Lin, 1989). The CCC was calculated as shown in Equation (x),

$$
\mathrm{CCC}=r \times \mathrm{C}_{\mathrm{b}}
$$

where

$$
\begin{aligned}
C_{\mathrm{b}} & =\left[\left(v+1 / v+u^{2}\right) / 2\right]^{-1} \\
v & =S_{0} / S_{\mathrm{p}} \\
u & =(\bar{P}-\bar{O}) /\left(S_{0} S_{p}\right)^{1 / 2}
\end{aligned}
$$

where $\bar{P}, \bar{O}, S_{o}$, and $S_{p}$ were defined above, and $v$ provides a measure of scale shift, and $\mu$ provides a measure of location shift. The CCC evaluates the degree of deviation between the best-fit line and the identity line $(y=x)$, therefore, the CCC of a model that is closer to 1 , is an indication of better model performance. Similar evaluation 
TAB LE 5 Intercontinental $\mathrm{CH}_{4}$ yield prediction (g/kg DMI) prediction equations and model evaluations across regions

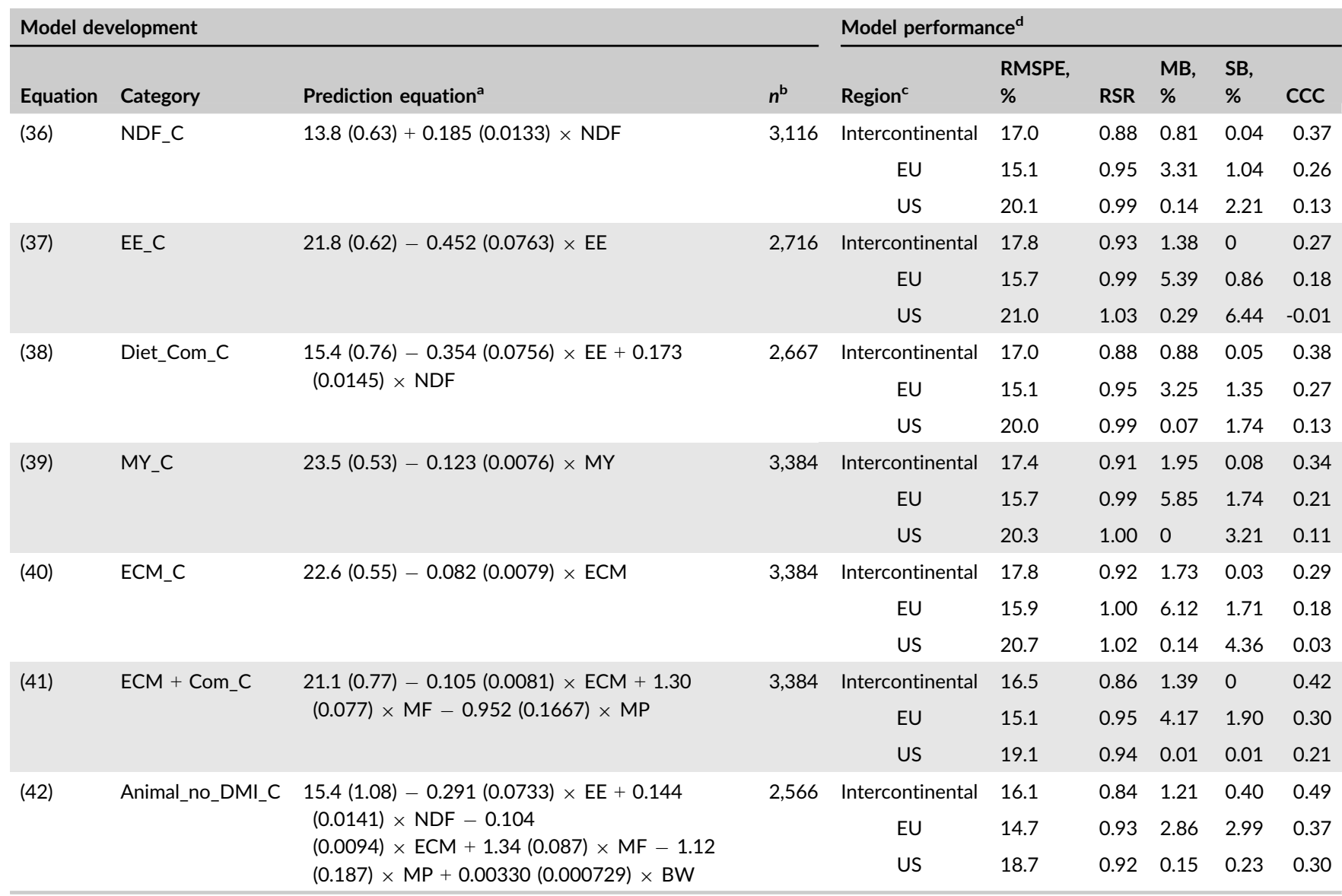

${ }^{a} \mathrm{GEl}$, gross energy intake (MJ/day); DMI, dry matter intake (kg/day); NDF, dietary neutral detergent fiber concentration (\% of DM); EE, dietary ether extract concentration (\% of DM); MY, milk yield (kg/day); ECM, energy corrected milk (kg/day); MF, milk fat concentration (\%); MP, milk crude protein concentration (\%); BW, body weight (kg).

${ }^{b} n$, number of observations used to construct equations.

'EU, Europe; US, the United States of America; AU, Australia. Number of observations used for model performance cross-validation: Intercontinental $(\mathrm{EU}+\mathrm{US}+\mathrm{AU} ; n=2,566) ; \mathrm{EU}(n=1,423) ; \mathrm{US}(n=1,084)$.

${ }^{\mathrm{d}} \mathrm{RMSPE}$, Root mean square prediction error, expressed as a percentage of observed $\mathrm{CH}_{4}$ yield means; RSR, RMSPE-observations standard deviation ratio; $\mathrm{MB}$, mean bias as a percentage of MSPE, SB, slope bias as a percentage of MSPE; CCC, Concordance Correlation Coefficient.

approaches were conducted to test the performance of $\mathrm{CH}_{4}$ yield and intensity models. Currently, most national enteric $\mathrm{CH}_{4}$ inventories are based on models recommended by IPCC (1997, 2006). Therefore, IPCC models were also evaluated on both intercontinental and regional data sets.

\section{3 | RESULTS}

\section{1 | Database}

A general description of the data set collated and summary statistics of dietary composition, intake, milk production and composition, BW and $\mathrm{CH}_{4}$ emissions are presented in Table 1. In general, EU and US cows had similar DMI. However, DMI of US cows ranged from 3.9 to $35.4 \mathrm{~kg} /$ day, which was more variable than EU cows $(8.0$ to $33.5 \mathrm{~kg} /$ day). On average, US cows emitted less $\mathrm{CH}_{4}$ compared to EU cows (340 vs. $392 \mathrm{~g} /$ day per cow; Table 1). The $\mathrm{CH}_{4}$ production observations from the United States had a larger variability $\left[S_{0}=109 \mathrm{~g} /\right.$ day per cow and coefficient of variation $\left.(\mathrm{CV})=33 \%\right]$ than from $\mathrm{EU}\left[\mathrm{S}_{\mathrm{o}}=89 \mathrm{~g} /\right.$ day per cow and $\left.\mathrm{CV}=23 \%\right]$. Milk production of US cows was greater than that of EU cows, but MF and MP were greater in EU than US cows. Increased MF and MP were the primary factors causing daily ECM of EU cows to be $0.8 \mathrm{~kg} /$ day greater than that of US cows. Methane yield (g/kg DMI) and $\mathrm{CH}_{4}$ intensity $(\mathrm{g} / \mathrm{kg} \mathrm{ECM})$ in $\mathrm{EU}$ cows were greater than those of US cows by $18 \%$ and $6 \%$, respectively. The EU cows had a greater $\mathrm{CH}_{4}$ conversion factor $\left(Y_{\mathrm{m}}\right)$ compared to US cows (6.4\% vs. $5.4 \%$ ). Regardless of region, the majority of $\mathrm{CH}_{4}$ measurements were made using respiration chambers (70\%), while 23 and $6 \%$ of the observations were measured using the GreenFeed system and $\mathrm{SF}_{6}$ tracer technique, respectively.

Most of the US experimental diets (over 91\%) included corn silage, alfalfa hay, alfalfa silage, or grass hay as a forage source, but none included pasture. Frequently used concentrate ingredients in 


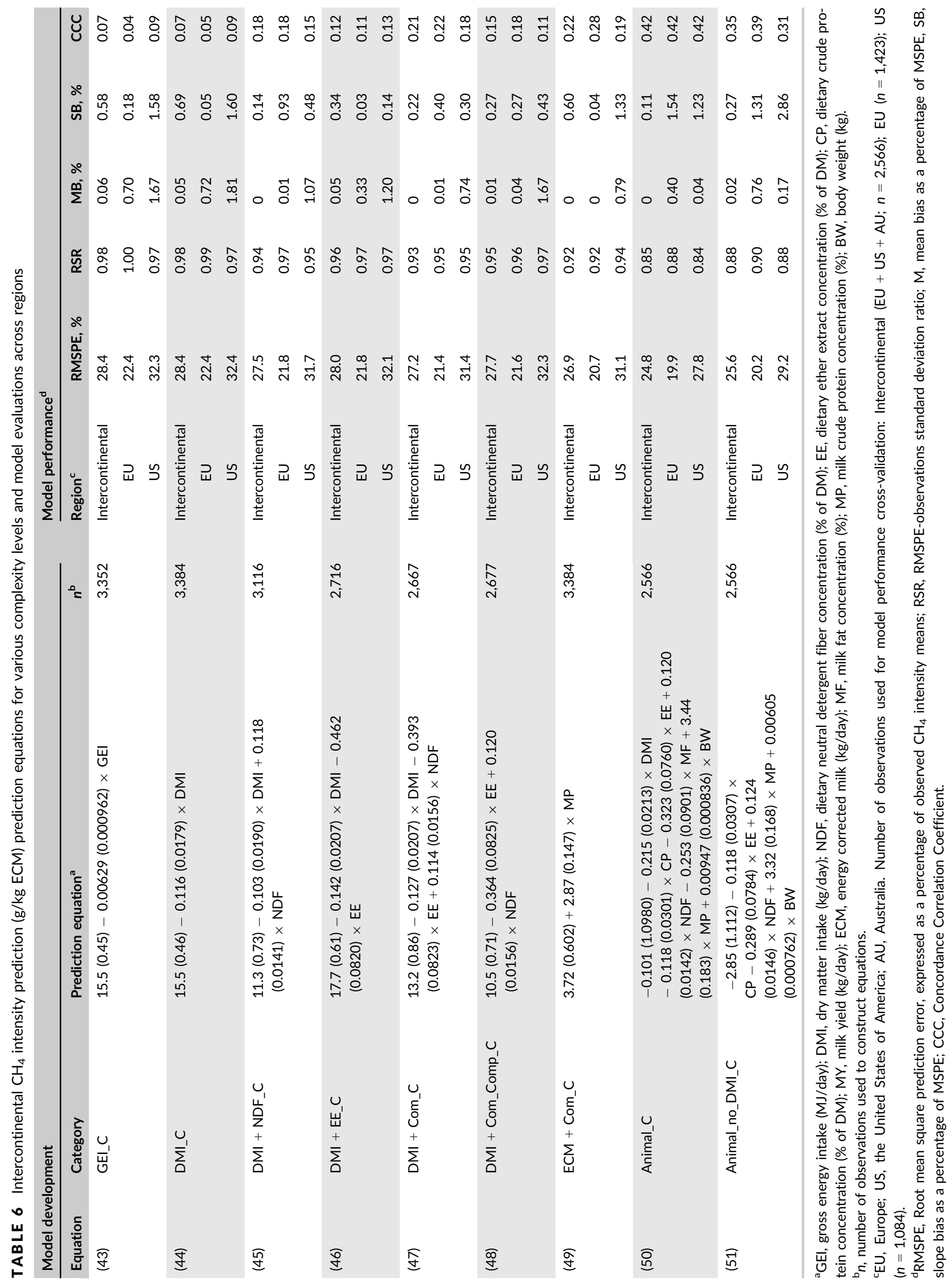


the United States were soybean meal, ground corn, and canola meal. In the EU experimental diets, the major forage sources were grass and corn silages, whereas the most frequently used concentrate sources were soybean meal, barley, and wheat. All cows from AU, $\mathrm{NZ}$, and $\mathrm{CL}$ in the database were fed pasture-based diets. Dietary CP concentration was similar for EU and US diets. The mean dietary concentration of EE was slightly greater for EU compared to US diets ( $3.6 \%$ vs. $3.3 \%$ of DM, Table 1$)$, and the median of dietary concentration of EE was proportionally greater for EU than US diets (3.5\% vs. 3.0\% of DM; data not shown). Experimental diets offered to EU cows had greater NDF concentration compared to those offered to US cows ( $36.6 \%$ vs. $33.3 \%$ of DM), which is consistent with increased forage:concentrate ratio in EU diets (data not shown). Similarly, the median of dietary concentration of NDF was proportionally greater for EU than US diets (37.7\% vs. $32.5 \%$ of DM; data not shown).

\subsection{Models for methane production}

\subsection{1 | Intercontinental models}

$\mathrm{CH}_{4}$ production prediction equations developed on intercontinental data and model performance indicators are shown in Table 2. As expected, GEI and DMI had a positive linear relationship with $\mathrm{CH}_{4}$ production and models based on these variables were of comparable accuracy with negligible bias. Adding dietary NDF to DMI (Equation 3) performed slightly better than one-variable models or adding dietary EE (Equation 4, Table 2). Although dietary compositions were available for selection in diet based category, only dietary NDF and EE concentrations along with DMI were selected as predictor variables (Equation 5, Table 2), which performed slightly better than those that used only DMI and EE but slightly worse than using DMI and NDF. Dietary NDF was positively correlated with $\mathrm{CH}_{4}$ production, while dietary $\mathrm{EE}$ had a negative relationship with $\mathrm{CH}_{4}$ production. When DMI was excluded, the resulting model (Equation 6) performed worse than any of the previous models. Using ECM and milk composition improved model performance compared with the equation that used MY only. All models using only milk production and composition variables tended to slightly under-predict at the higher end of production and overpredict at the low end of production (Figure 1). The best overall performance was when DMI, NDF, $\mathrm{EE}, \mathrm{MF}$, and $\mathrm{BW}$ were selected as predictors (Equation 10; RMSPE $=16.6 \%$ ). Taking DMI out of the potential variables selected showed reduced prediction performance indicating that DMI is a key variable in predicting $\mathrm{CH}_{4}$ production. The error decomposition of overall systematic bias remained negligible regardless of model complexity. Evaluation through CCC and MAE across different model categories was in agreement with RMSPE. Animal_C and $\mathrm{DMI}+\mathrm{NDF}_{-} \mathrm{C}$ models had the largest CCC $(0.76$ and 0.75 , respectively; Table 2) and the smallest MAE (47.5 and $48.5 \mathrm{~g} /$ day, respectively; Figure 1).

The predictive ability of intercontinental models on regional data set (EU and US) was also evaluated using RSR. The intercontinental models had a larger RSR (averaging 0.73) on EU observations compared to using all data (averaging 0.70). A greater amount of systematic biases (both $\mathrm{MB}$ and $\mathrm{SB}$ ) was observed with $\mathrm{CH}_{4}$ prediction for EU cows than for all cows when using intercontinental models (average $8 \%$ vs. $2 \%$, respectively). The predictive ability of intercontinental models on US observations was similar to the overall evaluation, and systematic biases were also similar (Table 2). The most recent IPCC Tier 2 model (IPCC, 2006) performed well on EU data with a low RMSPE (16.2\%) and moderate SB (9.6\%). The older IPCC Tier 2 model (IPCC, 1997) had a better performance on intercontinental and US data compared to IPCC (2006), but was marginally worse on EU data. Both IPCC models had a less favorable prediction performance for US cows compared to almost all equations developed on the intercontinental data, whereas it was marginally worse for EU cows, in part because the equations were developed on the current data.

\subsection{2 | Regional models (EU)}

Models developed on the EU database and model evaluations are presented in Table 3. The internal EU model evaluations based on EU observations and model comparisons across different categories followed a trend similar to the intercontinental prediction models. Adding NDF to DMI improved model accuracy compared to using either DMI or GEI alone or adding EE to DMI (Table 3). A model with dietary concentrations without DMI did not perform as well as models in previous categories. Models using ECM and milk composition performed better than those using MY only. When all predictors were available for selection, DMI, dietary EE, dietary NDF, MF, and BW were selected and had a similar performance $(\mathrm{RMSPE}=14.6 \%$, Equation 23) as the DMI + NDF. Once again, if DMI was taken out, prediction accuracy became worse (RMSPE $=15.8 \%$, Equation 24). Similar to RMSPE, evaluation through CCC and MAE also indicated that models using DMI + NDF and all variables had better prediction accuracy compared to the other models $(C C C=0.72$ and 0.72 , respectively; Table 3) and (MAE $=44.9$ and $44.5 \mathrm{~g} /$ day, respectively; Figure 2). In addition, the intercontinental and EU models had similar overall performance for predicting enteric $\mathrm{CH}_{4}$ production of $\mathrm{EU}$ cows (mean $=0.73$ and 0.72 , respectively). However, systematic biases were proportionally smaller for EU models compared to intercontinental models ( $4 \%$ vs. $8 \%$, respectively). Furthermore, all categories of models based on the EU database had smaller RSR (mean $=0.72$ ) when used to predict $\mathrm{CH}_{4}$ production in $\mathrm{EU}$ cows compared to prediction for US cows (mean $=0.80$ ). There was significant MB when EU models were evaluated against US data (Table 3).

\subsection{3 | Regional models (US)}

Models developed on US data and model evaluations are shown in Table 4. Single variable models using GEI (Equation 25) or DMI (Equation 26) had similar predictive ability when evaluated using US observations, and systematic biases were negligible in both models. 


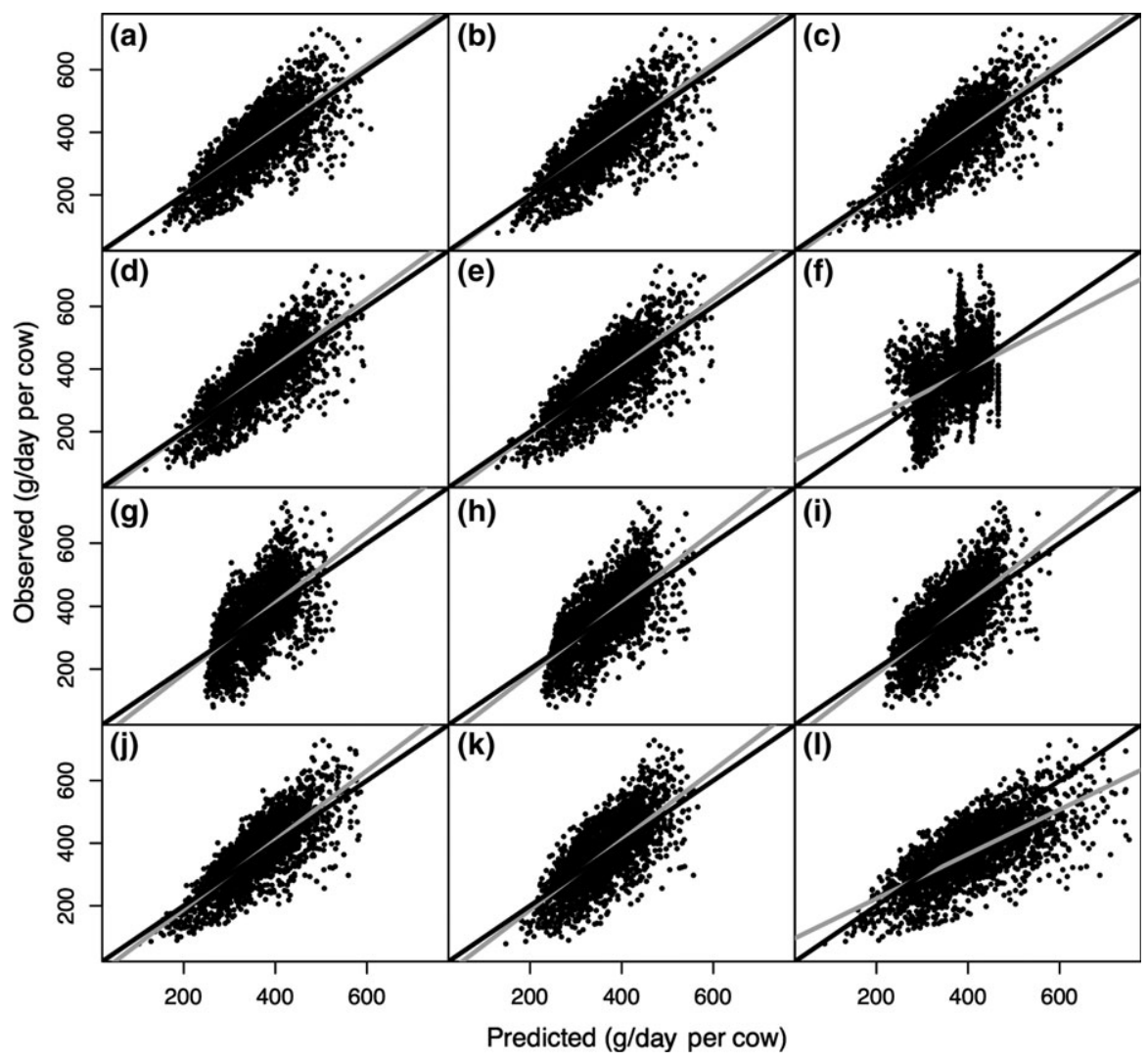

FIGURE 1 Predicted vs. observed value plots based on Intercontinental $\mathrm{CH}_{4}$ production (g/day per cow) prediction equations at different complexity levels of (a) GEI_C (gross energy intake), (b) DMI_C (dry matter intake), (c) DMI + NDF_C (dry matter intake and dietary neutral detergent fiber concentration), (d) DMI + EE_C (dry matter intake and dietary ether extract concentration), (e) DMI + Com_C (DMI and all dietary composition), (f) Diet_Com_C (all available dietary composition only), (g) MY_C (milk yield), (h) ECM_C (energy corrected milk yield), (i) ECM + Com_C (energy corrected milk and milk composition), (j) Animal_C (all available variables), (k) Animal_no_DMI_C (all available variables except DMI), and (I) IPCC Tier 2 (2006) models for lactating dairy cows based on Intercontinental (Europe + US + Australia; $n=2,566$ ) data. The corresponding mean absolute errors (MAE, g/day) are $M A E_{a}=50.9, M E_{b}=50.3, M_{c} E_{c}=48.5, M A E_{d}=51.1, M A E_{e}=49.2$,

$\mathrm{MAE}_{\mathrm{f}}=73.2, \mathrm{MAE}_{\mathrm{g}}=62.8, \mathrm{MAE}_{\mathrm{h}}=58.9, \mathrm{MAE}_{\mathrm{i}}=57.5, \mathrm{MAE}_{\mathrm{j}}=47.5, \mathrm{MAE}_{\mathrm{k}}=55.1$, and $\mathrm{MAE}_{\mathrm{l}}=64.3$. The gray and black solid lines represent the fitted regression line for the relationship between predicted and observed values and the identity line $(y=x)$, respectively

Only DMI and dietary NDF concentration were selected from all diet composition, which provided the same prediction equation as the DMI + NDF model (Equations 27 and 29). In contrast to intercontinental and $\mathrm{EU}$ based models, $\mathrm{CH}_{4}$ production prediction accuracy of US cows was not improved by the addition of any dietary composition in the model. ECM and milk component based models had smaller RMSPE (24.8\% and $24.3 \%$, respectively) compared to the MY only based model (26.5\%). Consistently, the model containing the most variables also had the smallest RMSPE across all categories (19.8\%, Equation 34; Table 4), and had the greatest CCC (0.77) and the smallest MAE (51.7 g/day; Figure 3). When DMI was not considered as a candidate in the prediction equation, ECM was selected instead in the model (Equation 35). Models without DMI had greater RMSPE compared to other categories with DMI in the model. The intercontinental models had similar overall performance for predicting enteric $\mathrm{CH}_{4}$ production of US observations compared to US models (mean RSR $=0.71$ vs. 0.71 , respectively), as both were associated with negligible systematic biases (Table 4). All categories of US models performed better when predicting $\mathrm{CH}_{4}$ production from
US cows compared with predicting for EU cows (mean RSR $=0.71$ vs. 0.82 , respectively). Significant increment on both $M B$ and $S B$ were observed when predicting $\mathrm{CH}_{4}$ production of $\mathrm{EU}$ cows using models based on the US data.

\section{3 | Models for methane yield}

Intercontinental $\mathrm{CH}_{4}$ yield (g/kg DMI) prediction models of various complexity levels and with evaluations based on different datasets are shown in Table 5. Results for the regional based models of $\mathrm{CH}_{4}$ yield are given in Tables S1 and S2 for EU and US, respectively. In both intercontinental and regional models, we observed positive associations between dietary NDF concentration, MF, and BW with $\mathrm{CH}_{4}$ yield and negative associations between EE, MY, MP, and ECM with $\mathrm{CH}_{4}$ yield. Using only $\mathrm{EE}, \mathrm{MY}$ or $\mathrm{ECM}$ had similar predictive ability for $\mathrm{CH}_{4}$ yield (average of these three categories RMSPE $=17.7 \%, 15.7 \%$, and $20.7 \%$ for intercontinental, EU, and US regions, respectively). When all variables were considered, the resultant model had negligible systematic biases and the smallest RMSPE 


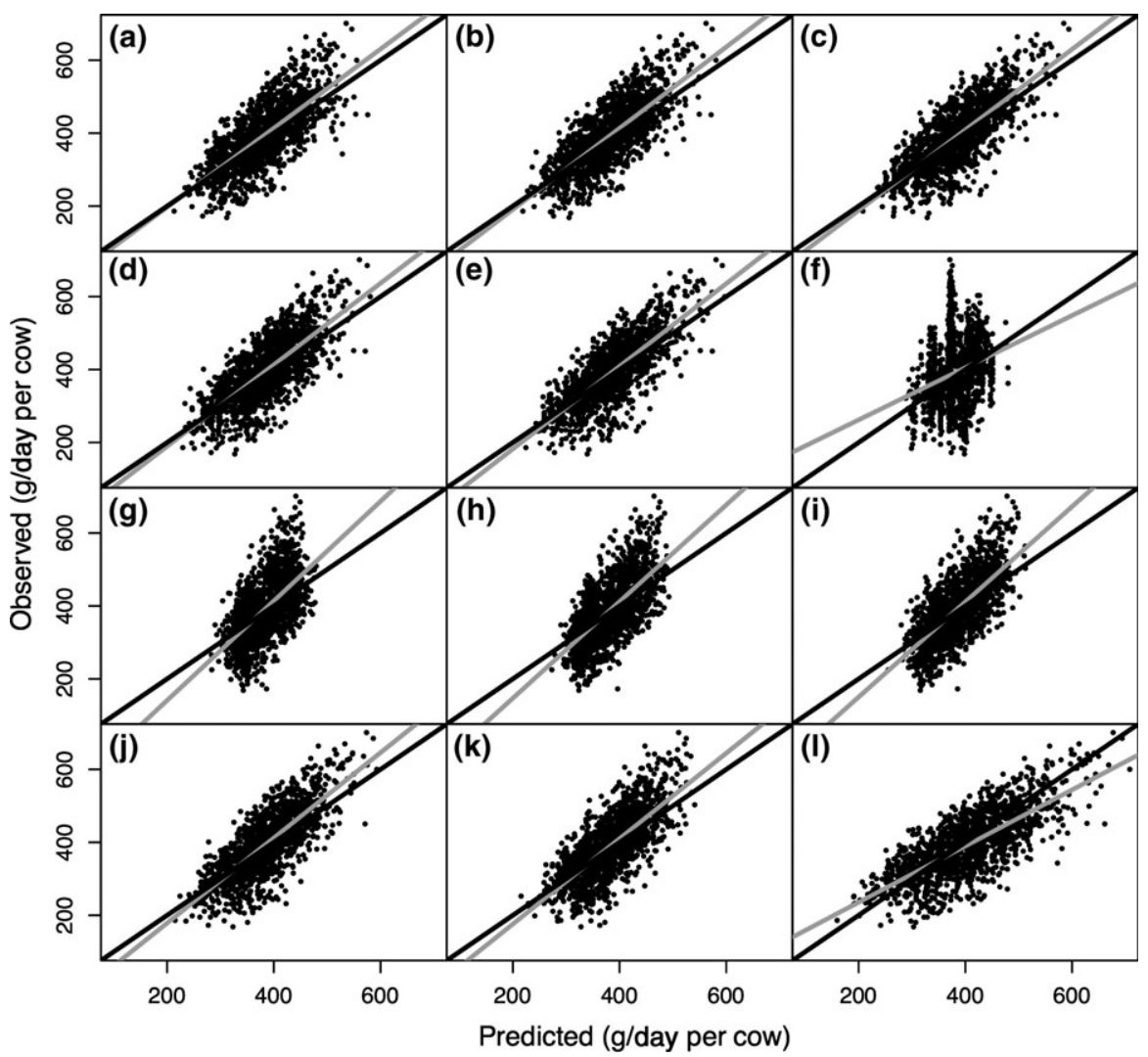

FIGURE 2 Predicted vs. observed value plots based on European $\mathrm{CH}_{4}$ production ( $\mathrm{g}$ /day per cow) prediction equations at different complexity levels of (a) GEI_C (gross energy intake), (b) DMI_C (dry matter intake), (c) DMI + NDF_C (dry matter intake and dietary neutral detergent fiber concentration), (d) DMI + EE_C (dry matter intake and dietary ether extract concentration), (e) DMI + Com_C (DMI and all dietary composition), (f) Diet_Com_C (all available dietary composition only), (g) MY_C (milk yield), (h) ECM_C (energy corrected milk yield), (i) $\mathrm{ECM}+\mathrm{Com}_{-} \mathrm{C}$ (energy corrected milk and milk composition), (j) Animal_C (all available variables), (k) Animal_no_DMI_C (all available variables except DMI), and (I) IPCC Tier 2 (2006) models for lactating dairy cows based on European $(n=1,423)$ data. The corresponding mean absolute errors (MAE, g/day) are $\mathrm{MAE}_{\mathrm{a}}=48.6, \mathrm{MAE}_{\mathrm{b}}=46.3, \mathrm{MAE}_{\mathrm{c}}=44.9, \mathrm{MAE}_{\mathrm{d}}=46.3, \mathrm{MAE}_{\mathrm{e}}=44.6, \mathrm{MAE}_{\mathrm{f}}=65.8, \mathrm{MAE}_{\mathrm{g}}=56.1, \mathrm{MAE}_{\mathrm{h}}=52.7$, $M A E_{i}=51.6, M A E_{j}=44.5, M A E_{k}=50.0$, and $M A E_{1}=50.7$. The gray and black solid lines represent the fitted regression line for the relationship between predicted and observed values and the identity line $(y=x)$, respectively

across all categories (RMSPE $=16.1 \%$, Equation 42; Table 5). The CCC and MAE analyses also confirmed that it was the best performing model (Tables 5, S1, and S2). Such findings were also observed in EU and US regional models (Equations 58 and 65, RMSPE $=14.8 \%$ and $18.6 \%$, respectively; Tables S1 and S2, respectively). Using milk components as model variables resulted in the second-best model in all regions. Furthermore, the intercontinental models had a similar RSR while predicting EU or US observations (mean $=0.97$ and 0.98 , respectively), compared to predicting $\mathrm{CH}_{4}$ yield using EU and US regional models (Figures S1-S3).

\section{4 | Models for methane intensity}

Intercontinental $\mathrm{CH}_{4}$ intensity $(\mathrm{g} / \mathrm{kg} \mathrm{ECM})$ prediction models of various complexity levels and with model evaluations based on different datasets are shown in Table 6, and results for the regional models for EU, and the US are shown in Tables S3 and S4, respectively. We consistently observed negative relationships between GEI, DMI, and dietary $\mathrm{EE}$ concentration with $\mathrm{CH}_{4}$ intensity, and positive relationships between MP, BW and dietary NDF concentration with $\mathrm{CH}_{4}$ intensity. However, models that were based on GEI, DMI, or dietary composition did not predict $\mathrm{CH}_{4}$ intensity well. Substantial improvement in prediction accuracy was observed when milk component and animal variables were included in the model. Similar to $\mathrm{CH}_{4}$ production and yield models, intercontinental models performed well for both EU and US cows (Figures S4-S6). Models that included the most variables had the greatest $\mathrm{CCC}$ and the smallest MAE compared to all other categories in all regions.

\section{4 | DISCUSSION}

\subsection{Key predictor variables for methane emission}

This study identified key predictor variables for $\mathrm{CH}_{4}$ production (g/ day per cow), yield (g/kg DMI), and intensity ( $/ \mathrm{kg} \mathrm{ECM}$ ) in lactating dairy cows from different regions of the world and evaluated the trade-off between the availability of input variables and prediction accuracy of models. The analysis confirmed that DMI is the most 


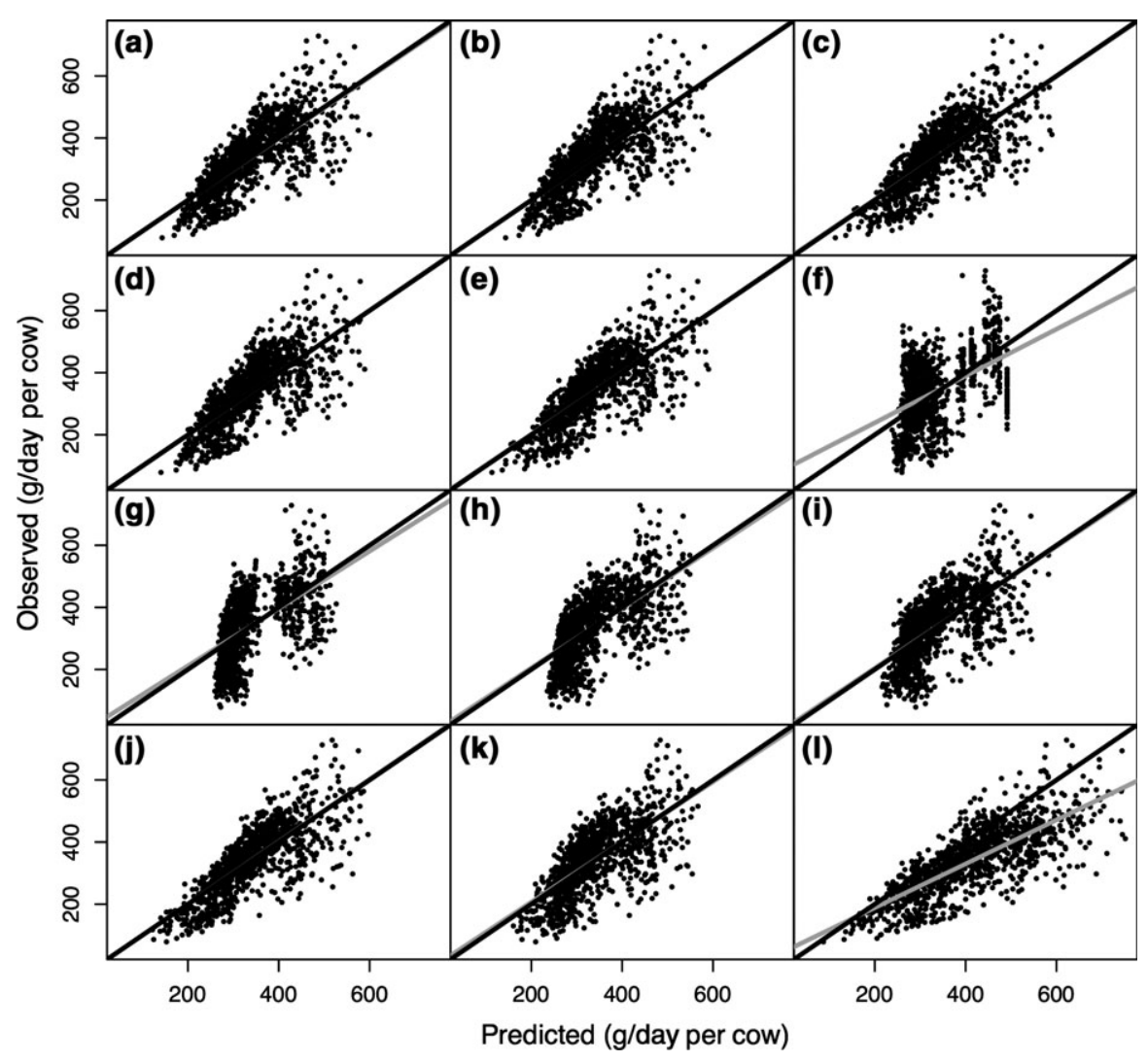

FIGURE 3 Predicted vs. observed value plots based on US $\mathrm{CH}_{4}$ production (g/day per cow) prediction equations at different complexity levels of (a) GEI_C (gross energy intake), (b) DMI_C (dry matter intake), (c) DMI + NDF_C (dry matter intake and dietary neutral detergent fiber concentration), (d) DMI + EE_C (dry matter intake and dietary ether extract concentration), (e) DMI + Com_C (DMI and all dietary composition), (f) Diet_Com_C (all available dietary composition only), (g) MY_C (milk yield), (h) ECM_C (energy corrected milk yield), (i) ECM + Com_C (energy corrected milk and milk composition), (j) Animal_C (all available variables), (k) Animal_no_DMI_C (all available variables except DMI), and (I) IPCC Tier 2 (2006) models for lactating dairy cows based on US $(n=1,084)$ data. The corresponding mean absolute errors

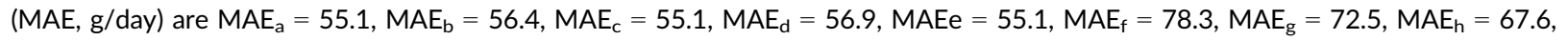
$M A E_{i}=65.8, M A E_{j}=51.7, M A E_{k}=62.4$, and $M A E_{1}=83.6$. The gray and black solid lines represent the fitted regression line for the relationship between predicted and observed values and the identity line $(y=x)$, respectively

important variable to predict enteric $\mathrm{CH}_{4}$ production in dairy cattle, which agrees with previous research (e.g., Hristov et al., 2013; Kriss, 1930; Reynolds, Crompton, \& Mills, 2011). There was a significant positive relationship between $\mathrm{DMI}$ and $\mathrm{CH}_{4}$ production demonstrating that as a dairy cow consumes more feed, more $\mathrm{CH}_{4}$ is produced due to greater availability of substrate for microbial fermentation. The majority of extant prediction models for $\mathrm{CH}_{4}$ production included DMI as a predictor variable, and evaluation of models developed in this study across various complexity levels also indicated that DMI had the greatest effect on the amount of $\mathrm{CH}_{4}$ produced. The slopes of DMI to $\mathrm{CH}_{4}$ production ranged from 13.0 to $15.3 \mathrm{~g}$ of $\mathrm{CH}_{4} / \mathrm{kg}$ of DMI for EU cows (Table 3) when other covariates were kept constant. The corresponding values were smaller for US cows and ranged from 11.3 to $12.3 \mathrm{~g}$ of $\mathrm{CH}_{4} / \mathrm{kg}$ of DMI (Table 4). This is probably due to the difference in dietary composition between EU and US diets and the digestibility of these diets, as EU diets contained proportionally more forage. Practically, it is unlikely that one variable (e.g., dietary NDF concentration) would be different while the rest remain constant because of the associated exchange for other nutrients in ingredients used to formulate diets. In addition, the slopes can only be interpreted in combination with the intercept in all equations. Nevertheless, these results provide insights in assessing the impact of explanatory factors on the variability of $\mathrm{CH}_{4}$ production among different regions. Increased intake may potentially increase passage rate and shorten digesta retention time in the rumen, thus decreasing rumen fermentation and organic matter digestibility, which ultimately decrease $\mathrm{CH}_{4}$ production per unit of feed (Boadi, Benchaar, Chiquette, \& Masse, 2004). Methane yield has been reported to have a negative relationship with DMI (Moe \& Tyrrell, 1979). Johnson and Johnson (1995) reported that for every kg of increase in DMI, there is, on average, a $1.6 \%$ decrease of feed GE lost through $\mathrm{CH}_{4}$. A more recent study also confirmed $2.1 \%$ reduction on $Y_{m}$ per $\mathrm{kg}$ of DMI increase from dairy cows (Warner, Bannink, Hatew, van Laar, \& Dijkstra, 2017). Therefore, it is important to use different $Y_{m}$ values depending on level of production, which accounts for intake and digestibility of nutrients. In the present study, DMI was not considered as a predictor for $\mathrm{CH}_{4}$ yield, and MY or ECM was not used for prediction of $\mathrm{CH}_{4}$ intensity because these variables already have 
been used for the calculation of reported $\mathrm{CH}_{4}$ yield or intensity. However, negative relationships between $\mathrm{CH}_{4}$ yield and $\mathrm{MY}$ (or ECM), and between $\mathrm{CH}_{4}$ intensity and DMI were observed because of the overall positive relationship between $\mathrm{MY}$ and $\mathrm{DMI}$, which is in close agreement with previous reports (e.g., Johnson \& Johnson, 1995; Moe \& Tyrrell, 1979; Warner et al., 2017).

In agreement with Kebreab et al. (2008) and Appuhamy et al. (2016), IPCC (2006), the Tier 2 model overpredicted $\mathrm{CH}_{4}$ production of US cows in our database by $22 \%$, whereas it performed well on EU cows mainly because the $Y_{m}$ in IPCC Tier 2 (6.5\%) was similar to the average $Y_{m}$ of EU cows (6.4\%) in our database. There was a moderate SB of the IPCC (2006) Tier 2 model for EU cows probably due to the absence of an intercept in the IPCC model. The $Y_{m}$ for US cows in our database (5.4\%) was close to that reported by Kebreab et al. (2008) and Appuhamy et al. (2016) for US cows. This illustrates that it is important to either use a regional model or intercontinental model that was developed using representative samples from each region. Furthermore, the GEl-based models appear to perform better and are associated with small systematic biases when they include an intercept term as for the GEI_C models developed in the present study.

Dietary NDF concentration was selected previously as the key dietary variable to predict enteric $\mathrm{CH}_{4}$ production of dairy cows across regions (Moe \& Tyrrell, 1979; Nielsen et al., 2013). Dietary NDF, the majority of which is from forage, represents the amount of structural carbohydrates in the diet. The type of carbohydrates (structural or non-structural) in the diet has been shown to influence volatile fatty acid (VFA) profile in the rumen, and in turn, enteric $\mathrm{CH}_{4}$ production (Russell \& Wallace, 1997; Van Soest, 1994). Studies focused on the effect of type of carbohydrates indicate that diets rich in non-structural carbohydrates such as starch and sugars are more likely to favor propionate formation, resulting in less hydrogen $(H)$ and $\mathrm{CH}_{4}$ production, whereas diets rich in structural carbohydrates generally favor acetate and butyrate production by net $\mathrm{H}$ producers (Bannink et al., 2008; Johnson \& Johnson, 1995; Moe \& Tyrrell, 1979). Consistent with effects of digestion and fermentation kinetics on $\mathrm{CH}_{4}$ emission, coefficients of NDF in all models developed were significantly positive in the present study. Methane production ranged from 2.80 to $3.42 \mathrm{~g}$ of $\mathrm{CH}_{4} / \%$ of dietary NDF for EU cows, when the other covariates were kept constant. The corresponding values were smaller for US cows and ranged from 2.30 to $2.59 \mathrm{~g}$ of $\mathrm{CH}_{4} / \%$ of dietary NDF (excluding categories without DMI term). Such findings could result from dietary differences between EU and US. The forage quality in the diet, specifically fiber digestibility, plays an important role in enteric $\mathrm{CH}_{4}$ production (Brask, Lund, Hellwing, Poulsen, \& Weisbjerg, 2013; Warner et al., 2016), and it has been shown that $\mathrm{CH}_{4}$ production of cows tends to increase with increasing diet organic matter digestibility (Ramin \& Huhtanen, 2013). The EU diets containing more forage have an inherently greater digestibility of NDF than more concentrate-based US diets where the lower ruminal $\mathrm{pH}$ in the high grain diets inhibits the growth of methanogens and protozoa, in turn, hampering NDF digestion and $\mathrm{CH}_{4}$ production in the rumen (Hegarty, 1999). In agreement with Ramin and Huhtanen (2013), Appuhamy et al. (2016) also reported that prediction models for $\mathrm{CH}_{4}$ production with digestible dietary NDF concentration had a better performance than the model with dietary NDF concentration in US cows. This indicated that there is potential to further enhance prediction accuracy if dietary acid detergent fiber concentration or apparent total-tract digestibility of NDF is known. Besides the effect of dietary NDF concentration on total $\mathrm{CH}_{4}$ production, cows fed high NDF concentration diets tend to produce more $\mathrm{CH}_{4}$ per unit of DMI which can also result from the higher ruminal $\mathrm{pH}$ (Knapp, Laur, Vadas, Weiss, \& Tricarico, 2014; Pinares-Patiño, Waghorn, Hegarty, \& Hoskin, 2009). Furthermore, substituting high-fiber forage for the optimal amount of more digestible carbohydrate or low fiber sources will increase milk production, and decrease ruminal $\mathrm{pH}$ and fiber digestibility, and both lead to a reduction in $\mathrm{CH}_{4}$ intensity (Boadi et al., 2004; Leng, 1993). Consistent with expectations, both enteric $\mathrm{CH}_{4}$ yield and intensity declined as dietary NDF concentration decreased in the present evaluation.

Dietary EE concentration was also identified as a key dietary predictor variable in $\mathrm{EU}$ and intercontinental enteric $\mathrm{CH}_{4}$ production prediction models, but its impact on the predictive ability of US models was minimal. Dietary EE concentration may be increased by using herbage in young, leafy stage rather than in more mature, stemmy stage (Warner et al., 2016), or by lipid supplementation of the diet, and is an indicator of the amount of lipid consumed relative to other dietary components (Martin et al., 2016). The effect of lipid supplementation on enteric $\mathrm{CH}_{4}$ production has been extensively studied and lipid supplementation is a well-recognized mitigation strategy as reviewed by several groups (e.g., Beauchemin, Kreuzer, O'Mara, \& McAllister, 2008; Knapp et al., 2014; Martin, Morgavi, \& Doreau, 2010). Lipids reduce $\mathrm{CH}_{4}$ production by suppressing the protozoa and methanogen population in the rumen, decrease NDF digestibility, and reduce the total amount of organic matter fermented, resulting in lower $\mathrm{CH}_{4}$ production (Guyader et al., 2014; Machmüller \& Kreuzer, 1999; Van Nevel \& Demeyer, 1996). Finally, lipids may cause a reduction in DMI, due to their high energy density and effects on gut fill and appetite, which could lead to less $\mathrm{CH}_{4}$ production (Allen, 2000; Hollmann et al., 2012). Consistent with the above-mentioned studies and data summarized by Grainger and Beauchemin (2011), slopes of the EE variable in the EU prediction models were significantly negative. The absence of dietary EE in US models, and small slope when EE was forced in US models, might be due to the relatively lower EE concentration in the US diets. In addition, the magnitude of reduction has not always been consistent, with some studies reporting a 3.5\% (Moate et al., 2011) and a $5.6 \%$ (Beauchemin et al., 2008) decrease in $\mathrm{CH}_{4}$ yield for $1 \%$ increase in dietary EE concentration and others reporting an almost negligible $\mathrm{CH}_{4}$ reduction (Eugène, Masse, Chiquette, \& Benchaar, 2008). As noted above, dietary lipids can have a negative effect on fiber digestibility in the rumen, DMI, and potentially, MY in dairy cows (Hristov et al., 2013). However, such effects may strongly vary among studies, depending on the compensation of increased energy density to the reduction in fiber digestibility and DMI.

Body weight was one of the variables selected for prediction of $\mathrm{CH}_{4}$ production. As noted by Smith and Baldwin (1974) and Demment and Van Soest (1985), ruminal volume and weight are proportional to 
BW of dairy cows. Consequently, smaller animals, with a lower maintenance energy requirement, ingest less feed and have less $\mathrm{CH}_{4}$ production (Hristov et al., 2013). In addition, simulations with a dynamic mechanistic model indicated that the DMI/BW ratio is an important factor for $\mathrm{CH}_{4}$ production; consuming same amount of feed intake, smaller cows tend to produce less $\mathrm{CH}_{4}$ as ruminal passage rate is likely to be faster due to greater DMI/BW ratio (Huhtanen, Ramin, \& Cabezas-Garcia, 2016; Huhtanen, Ramin, \& Udén, 2015), which has been shown to reduce $\mathrm{CH}_{4}$ yield (Goopy et al., 2014). Therefore, BW could affect $\mathrm{DMI}$ and passage rate of ruminal digesta, which will lead to differences in feed digestibility and VFA production, ultimately affecting $\mathrm{CH}_{4}$ production. A positive relationship was observed between BW and $\mathrm{CH}_{4}$ production in our evaluation, which agrees with previous research (Hristov et al., 2013; Moraes et al., 2014).

\subsection{Selection of the best models}

In the current study, the trade-off between model complexity and predictive ability has been evaluated. In general, improvement in model goodness-of-fit has been reported as the model structure becomes more complex (e.g., Moraes et al., 2014; Santiago-Juarez et al., 2016). An evaluation of whole-farm $\mathrm{CH}_{4}$ production models demonstrated poor performance and greater systematic biases when equations did not include dietary variables (Ellis et al., 2010). In the present study, models were categorized and different levels of potential predictor variables were sequentially added during the model development process. We observed that accuracy of prediction of $\mathrm{CH}_{4}$ production improved in models that include DMI, dietary composition, milk production and composition, and BW. In particular, complex models that used all available variable information consistently improved prediction performance compared to simpler models. Models using only MY or dietary composition were the least accurate. When DMI was omitted from the model to predict $\mathrm{CH}_{4}$ production, ECM was selected instead due to its high correlation with $\mathrm{DMI}$, but model predictive ability was reduced. Although intercontinental models were developed based on a data set containing a slightly greater proportion of EU data compared to US data ( $55 \%$ vs. $42 \%$, respectively), the intercontinental models seem to perform well on both regions without significant biases. In addition, the variable inputs required to improve predictions are not always available from commercial dairy farms, for example, $\mathrm{DMI}$ and BW of individual dairy cows. Milk yield and milk components are generally available in practice, but $\mathrm{CH}_{4}$ production was not predicted well by these input variables. Considering the number of variables required and prediction performance we recommend the equation with DMI + NDF concentration to be used for enteric $\mathrm{CH}_{4}$ production. A recent evaluation of extant models using estimated DMI vs. actual DMI measurements indicated enteric $\mathrm{CH}_{4}$ emissions could be predicted satisfactorily without DMI measurements for North America, but not for Australia and New Zealand, with accuracy of prediction using Europe data in between (Appuhamy et al., 2016). However, estimation of DMI is still a challenge for dairy farmers in practice because voluntary DMI prediction equations require individual animal information and, in particular BW (Fox, Sniffen, O'Connor, Russell, \&
Van Soest, 1992; NRC, 2001; Vazquez \& Smith, 2000). In this respect, using average or total intake from a group of cows or the whole herd instead of individual measurements could be an alternative for wholefarm enteric $\mathrm{CH}_{4}$ emission estimates, when cows are grouped by milk production, BW, or parity in commercial dairy farms.

Model evaluations across various complexity levels indicated that $\mathrm{CH}_{4}$ yield of lactating dairy cows could be predicted successfully with milk production and composition or dietary composition based models. The corresponding intercontinental models were able to make comparable predictions for EU and US cows relative to the regional EU and US models. The best prediction of $\mathrm{CH}_{4}$ intensity could be achieved with the most complex model (Animal_C), with the model for the intercontinental data set also able to make accurate predictions for both EU and US cows. Although overall predictive performance was similar, it should be noted that actual predictions based on the model derived from intercontinental data may differ from the model based on regional-specific data, because the slopes of the variables included in these models differ.

Finally, it is important to note that the majority of data used in this study was from temperate regions and there is a scarcity of dairy cow data from tropical regions, which differ in breeds and the quality of forage fed. Many developing countries are in the tropical regions, and milk production rather than GHG emissions is still the top priority in those countries (FAO, 2016). Therefore, further research on determinants and predictors of $\mathrm{CH}_{4}$ emission applicable to animals in the tropics is warranted. In addition, spatial auto correlations should also be considered to incorporate the effects of environmental factors once a broader database becomes available in the future.

In summary, our analysis based on a relatively large dataset from the GLOBAL NETWORK project, indicated that the ability to predict enteric $\mathrm{CH}_{4}$ production increases with increasing model complexity. As observed previously, DMI is the key factor for enteric $\mathrm{CH}_{4}$ production prediction. Although complex models that use DMI, NDF, $\mathrm{EE}, \mathrm{MF}$, and $\mathrm{BW}$ had the best performance for predicting $\mathrm{CH}_{4}$ production, models requiring only DMI or DMI + NDF had the second best predictive ability and offer an alternative to complex models. Milk production and composition variables are key factors to predict $\mathrm{CH}_{4}$ yield, whereas milk composition and animal variables are key factors to predict $\mathrm{CH}_{4}$ intensity. Model evaluation specific to individual regions compared with that of intercontinental based models suggests that enteric $\mathrm{CH}_{4}$ production, yield, and intensity can be accurately predicted from both intercontinental models and regionalspecific models with similar performance. Although prediction performance was similar, intercepts and slopes of variables in optimal prediction equations developed on intercontinental basis differed from those developed on regional basis. Therefore, revised $\mathrm{CH}_{4}$ emission conversion factors for specific regions are preferred to improve $\mathrm{CH}_{4}$ production estimates in national inventories.

\section{ACKNOWLEDGEMENTS}

This study is part of the Joint Programming Initiative on Agriculture, Food Security and Climate Change (FACCE-JPI)'s "GLOBAL 
NETWORK" project and the "Feeding and Nutrition Network" (http:// animalscience.psu.edu/fnn) of the Livestock Research Group within the Global Research Alliance for Agricultural Greenhouse Gases (www.globalresearchalliance.org). Authors gratefully acknowledge funding for this project from: USDA National Institute of Food and Agriculture Grant no. 2014-67003-21979) University of California, Davis Sesnon Endowed Chair Program, USDA, and Austin Eugene Lyons Fellowship (University of California, Davis); Funding from USDA National Institute of Food and Agriculture Federal Appropriations under Project PEN 04539 and Accession number 1000803, DSM Nutritional Products (Basel, Switzerland), Pennsylvania Soybean Board (Harrisburg, PA, USA), Northeast Sustainable Agriculture Research and Education (Burlington, VT, USA), and PMI Nutritional Additives (Shoreview, MN, USA); the Ministry of Economic Affairs (the Netherlands; project BO-20-007-006; Global Research Alliance on Agricultural Greenhouse Gases), the Product Board Animal Feed (Zoetermeer, the Netherlands) and the Dutch Dairy Board (Zoetermeer, the Netherlands); USDA National Institute of Food and Agriculture (Hatch Multistate NC-1042 Project Number NH00616-R; Project Accession Number 1001855) and the New Hampshire Agricultural Experiment Station (Durham, NH); French National Research Agency through the FACCE-JPI program (ANR-13-JFAC-0003-01), Agricultural GHG Research Initiative for Ireland (AGRI-I), Academy of Finland (No. 281337), Helsinki, Finland; Swiss Federal Office of Agriculture, Berne, Switzerland; the Department for Environment, Food and Rural Affairs (Defra; UK); Defra, the Scottish Government, DARD, and the Welsh Government as part of the UK's Agricultural GHG Research Platform projects (www.ghgplatform.org.uk); INIA (Spain, project MIT01-GLOBALNET-EEZ); German Federal Ministry of Food and Agriculture (BMBL) through the Federal Office for Agriculture and Food (BLE); Swedish Infrastructure for Ecosystem Science (SITES) at Röbäcksdalen Research Station; Comisión Nacional de Investigación Científica y Tecnológica, Fondo Nacional de Desarrollo Científico y Tecnológico (Grant Nos. 11110410 and 1151355) and Fondo Regional de Tecnología Agropecuaria (FTG/RF-1028-RG); European Commission through SMEthane (FP7-SME-262270). The authors are thankful to all colleagues who contributed data to the GLOBAL NETWORK project and especially thank Luis Moraes, Ranga Appuhamy, Henk van Lingen, James Fadel, and Roberto Sainz for their support on data analysis. All authors read and approved the final manuscript. The authors declare that they have no competing interests.

\section{ORCID}

Ermias Kebreab iD http://orcid.org/0000-0002-0833-1352

\section{REFERENCES}

Allen, M. S. (2000). Effects of diet on short-term regulation of feed intake by lactating dairy cattle. Journal of Dairy Science, 83, 15981624. https://doi.org/10.3168/jds.S0022-0302(00)75030-2

Appuhamy, J. A. D. R. N., France, J., \& Kebreab, E. (2016). Models for predicting enteric methane emissions from dairy cows in North
America, Europe, and Australia and New Zealand. Global Change Biology, 22, 3039-3056. https://doi.org/10.1111/gcb.13339

Bannink, A., France, J., Lopez, S., Gerrits, W. J. J., Kebreab, E., Tamminga, S., \& Dijkstra, J. (2008). Modelling the implications of feeding strategy on rumen fermentation and functioning of the rumen wall. Animal Feed Science and Technology, 143, 3-26. https://doi.org/10.1016/ j.anifeedsci.2007.05.002

Bates, D., Maechler, M., Bolker, B., \& Walker, S. (2015). Fitting linear mixed-effects models using Ime4. Journal of Statistical Software, 67, $1-48$.

Beauchemin, K. A., Kreuzer, M., O'Mara, F., \& McAllister, T. A. (2008). Nutritional management for enteric methane abatement: A review. Australian Journal of Experimental Agriculture, 48, 21-27. https://doi. org/10.1071/EA07199

Bibby, J., \& Toutenburg, T. (1977). Prediction and improved estimation in linear models. Chichester, UK: John Wiley \& Sons.

Boadi, D., Benchaar, C., Chiquette, J., \& Masse, D. (2004). Mitigation strategies to reduce enteric methane emissions from dairy cows: Update review. Canadian Journal of Animal Science, 84, 319-335. https://doi.org/10.4141/A03-109

Brask, M., Lund, P., Hellwing, A. L. F., Poulsen, M., \& Weisbjerg, M. R. (2013). Enteric methane production, digestibility and rumen fermentation in dairy cows fed different forages with and without rapeseed fat supplementation. Animal Feed Science and Technology, 184, 67-79. https://doi.org/10.1016/j.anifeedsci.2013.06.006

Chai, T., \& Draxler, R. R. (2014). Root mean square error (RMSE) or mean absolute error (MAE)? - Arguments against avoiding RMSE in the literature. Geoscientific Model Development, 7, 1247-1250. https://doi. org/10.5194/gmd-7-1247-2014

Demment, M. W., \& Van Soest, P. J. (1985). A nutritional explanation for body-size patterns of ruminant and nonruminant herbivores. The American Naturalist, 125, 641-672. https://doi.org/10.1086/284369

Ellis, J. L., Bannink, A., France, J., Kebreab, E., \& Dijkstra, J. (2010). Evaluation of enteric methane prediction equations for dairy cows used in whole farm models. Global Change Biology, 16, 3246-3256. https://d oi.org/10.1111/j.1365-2486.2010.02188.x

Eugène, M., Masse, D., Chiquette, J., \& Benchaar, C. (2008). Meta-analysis on the effects of lipid supplementation on methane production in lactating dairy cows. Canadian Journal of Animal Science, 88, 331334. https://doi.org/10.4141/CJAS07112

FAO (2016). The state of food and agriculture. Rome, Italy: Food and Agriculture Organization of the United Nations.

Fox, D. G., Sniffen, C. J., O'Connor, J. D., Russell, J. B., \& Van Soest, P. J. (1992). A net carbohydrate and protein system for evaluating cattle diets: III. Cattle requirements and diet adequacy. Journal of Animal Science, 70, 3578-3596. https://doi.org/10.2527/1992. 70113578x

Gerber, P.J., Steinfeld, H., Henderson, B., Mottet, A., Opio, C., Dijkman, J., ... Tempio, G. (2013). Tackling climate change through livestock - A global assessment of emissions and mitigation opportunities. Rome, Italy: Food and Agriculture Organization of the United Nations (FAO).

Goopy, J., Donaldson, A., Hegarty, R., Vercoe, P., Haynes, F., Barnett, M., \& Oddy, V. (2014). Low-methane yield sheep have smaller rumens and shorter rumen retention time. British Journal of Nutrition, 111, 578-585. https://doi.org/10.1017/S0007114513002936

Grainger, C., \& Beauchemin, K. A. (2011). Can enteric methane emissions from ruminants be lowered without lowering their production? Animal Feed Science and Technology, 166-167, 308-320. https://doi.org/ 10.1016/j.anifeedsci.2011.04.021

Guyader, J., Eugène, M., Nozière, P., Morgavi, D., Doreau, M., \& Martin, C. (2014). Influence of rumen protozoa on methane emission in ruminants: A meta-analysis approach. Animal, 8, 1816-1825. https://doi. org/10.1017/S1751731114001852

Hammond, K. J., Crompton, L. A., Bannink, A., Dijkstra, J., Yáñez-Ruiz, D. R., O'Kiely, P., ... Reynolds, C. K. (2016). Review of current in vivo 
measurement techniques for quantifying enteric methane emission from ruminants. Animal Feed Science and Technology, 219, 13-30. https://doi.org/10.1016/j.anifeedsci.2016.05.018

Hegarty, R. S. (1999). Reducing rumen methane emissions through elimination of rumen protozoa. Australian Journal of Agricultural Research, 50, 1321-1327. https://doi.org/10.1071/AR99008

Hollmann, M., Powers, W. J., Fogiel, A. C., Liesman, J. S., Bello, N. M., \& Beede, D. K. (2012). Enteric methane emissions and lactational performance of Holstein cows fed different concentrations of coconut oil. Journal of Dairy Science, 95, 2602-2615. https://doi.org/10.3168/ jds.2011-4896

Hristov, A. N., Oh, J., Giallongo, F., Frederick, T. W., Harper, M. T., Weeks, H. L., ... Williams, S. R. O. (2015). An inhibitor persistently decreased enteric methane emission from dairy cows with no negative effect on milk production. Proceedings of the National Academy of Sciences of the United States of America, 112, 10663-10668. https://d oi.org/10.1073/pnas.1504124112

Hristov, A.N., Oh, J., Lee, C., Meinen, R., Montes, F., Ott, T., ... Oosting, S. (2013). Mitigation of greenhouse gas emissions in livestock production - A review of technical options for non- $\mathrm{CO}_{2}$ emissions. FAO Animal Production and Health Paper No. 177. Rome, Italy: FAO.

Huhtanen, P., Ramin, M., \& Cabezas-Garcia, E. H. (2016). Effects of ruminal digesta retention time on methane emissions: A modelling approach. Animal Production Science, 56, 501-506. https://doi.org/10. 1071/AN15507

Huhtanen, P., Ramin, M., \& Udén, P. (2015). Nordic dairy cow model Karoline in predicting methane emissions: 1 . Model description and sensitivity analysis. Livestock Science, 178, 71-80. https://doi.org/10. 1016/j.livsci.2015.05.009

IPCC (1997). Revised 1996 IPCC guidelines for national greenhouse gas inventories. Bracknell, UK: Intergovernmental Panel on Climate Change, IPCC/OECD/IEA.

IPCC (2006). 2006 IPCC guidelines for national greenhouse gas inventories. IGES, Kanagawa, Japan: Intergovernmental Panel on Climate Change.

James, G., Witten, D., Hastie, T., \& Tibshirani, R. (2014). An introduction to statistical learning: With applications in R. New York, NY: Springer.

Johnson, K. A., \& Johnson, D. E. (1995). Methane emissions from cattle. Journal of Animal Science, 73, 2483-2492. https://doi.org/10.2527/ 1995.7382483x

Kebreab, E., Clark, K., Wagner-Riddle, C., \& France, J. (2006). Methane and nitrous oxide emissions from Canadian animal agriculture: $\mathrm{A}$ review. Canadian Journal of Animal Science, 86, 135-158. https://doi. org/10.4141/A05-010

Kebreab, E., Johnson, K. A., Archibeque, S. L., Pape, D., \& Wirth, T. (2008). Model for estimating enteric methane emissions from United States dairy and feedlot cattle. Journal of Animal Science, 86, 2738 2748. https://doi.org/10.2527/jas.2008-0960

Knapp, J. R., Laur, G. L., Vadas, P. A., Weiss, W. P., \& Tricarico, J. M. (2014). Invited review: Enteric methane in dairy cattle production: Quantifying the opportunities and impact of reducing emissions. Journal of Dairy Science, 97, 3231-3261. https://doi.org/10.3168/jds. 2013-7234

Kriss, M. (1930). Quantitative relations of the dry matter of the food consumed, the heat production, the gaseous outgo and the insensible loss in body weight of cattle. Journal of Agricultural Research, 40, 283-295.

Kutner, M. H., Nachtsheim, C., Neter, J., \& Li, W. (2005). Applied linear statistical models. Boston, MA \& New York, NY: McGraw-Hill Irwin.

Leng, R. A. (1993). Quantitative ruminant nutrition - A green science. Australian Journal of Agricultural Research, 44, 363-380. https://doi. org/10.1071/AR9930363

Lin, L. I. (1989). A concordance correlation coefficient to evaluate reproducibility. Biometrics, 45, 255-268. https://doi.org/10.2307/2532051
Machmüller, A., \& Kreuzer, M. (1999). Methane suppression by coconut oil and associated effects on nutrient and energy balance in sheep. Canadian Journal of Animal Science, 79, 65-72. https://doi.org/10. 4141/A98-079

Martin, C., Ferlay, A., Mosoni, P., Rochette, Y., Chilliard, Y., \& Doreau, M. (2016). Increasing linseed supply in dairy cows diets based on hay or corn silage: Effect on enteric methane emission, rumen microbial fermentation, and digestion. Journal of Dairy Science, 99, 3445-3456. https://doi.org/10.3168/jds.2015-10110

Martin, C., Morgavi, D. P., \& Doreau, M. (2010). Methane mitigation in ruminants: From microbe to the farm scale. Animal, 4, 351-365. https://doi.org/10.1017/S1751731109990620

Moate, P. J., Williams, S. R. O., Grainger, C., Hannah, M. C., Ponnampalam, E. N., \& Eckard, R. J. (2011). Influence of cold-pressed canola, brewers grains and hominy meal as dietary supplements suitable for reducing enteric methane emissions from lactating dairy cows. Animal Feed Science and Technology, 166-167, 254-264. https://doi.org/10. 1016/j.anifeedsci.2011.04.069

Moe, P. W., \& Tyrrell, H. F. (1979). Methane production in dairy cows. Journal of Dairy Science, 62, 1583-1586. https://doi.org/10.3168/jds. S0022-0302(79)83465-7

Moraes, L. E., Strathe, A. B., Fadel, J. G., Casper, D. P., \& Kebreab, E. (2014). Prediction of enteric methane emissions from cattle. Global Change Biology, 20, 2140-2148. https://doi.org/10.1111/gcb.12471

Moriasi, D. N., Arnold, J. G., Van Liew, M. W., Bingner, R. L., Harmel, R. D., \& Veith, T. L. (2007). Model evaluation guidelines for systematic quantification of accuracy in watershed simulations. Transactions of the ASABE, 50, 885-900. https://doi.org/10.13031/2013.23153

Negussie, E., de Haas, Y., Dehareng, F., Dewhurst, R. J., Dijkstra, J., Gengler, N., ... Biscarini, F. (2017). Invited review: Large-scale indirect measurements for enteric methane emissions in dairy cattle: A review of proxies and their potential for use in management and breeding decisions. Journal of Dairy Science, 100, 2433-2453. https://doi.org/ 10.3168/jds.2016-12030

Nielsen, N. I., Volden, H., Akerlind, M., Brask, M., Hellwing, A. L. F., Storlein, T., \& Bertilsson, J. (2013). A prediction equation for enteric methane emission from dairy cows for use in NorFor. Acta Agriculturae Scandinavica, Section A - Animal Science, 63, 126-130. https://d oi.org/10.1080/09064702.2013.851275

NRC (2001). Nutrient requirements of dairy cattle, 7th revised edition. Washington, DC: National Research Council, National Academy Press.

Olijhoek, D. W., Hellwing, A. L. F., Brask, M., Weisbjerg, M. R., Højberg, O., Larsen, M. K., ... Lund, P. (2016). Effect of dietary nitrate level on enteric methane production, hydrogen emission, rumen fermentation, and nutrient digestibility in dairy cows. Journal of Dairy Science, 99, 6191-6205. https://doi.org/10.3168/jds.2015-10691

Pinares-Patiño, C. S., Waghorn, G. C., Hegarty, R. S., \& Hoskin, S. O. (2009). Effects of intensification of pastoral farming on greenhouse gas emissions in New Zealand. New Zealand Veterinary Journal, 57, 252-261. https://doi.org/10.1080/00480169.2009.58618

R Core Team (2016). R: A language and environment for statistical computing. Vienna, Austria: R Foundation for Statistical Computing. Retrieved from https://www.R-project.org/

Ramin, M., \& Huhtanen, P. (2013). Development of equations for predicting methane emissions from ruminants. Journal of Dairy Science, 96, 2476-2493. https://doi.org/10.3168/jds.2012-6095

Reynolds, C. K., Crompton, L. A., \& Mills, J. A. N. (2011). Improving the efficiency of energy utilization in cattle. Animal Production Science, 51, 6-12. https://doi.org/10.1071/AN10160

Russell, J. B., \& Wallace, R. J. (1997). Energy-yielding and energy-consuming reactions. In P. N. Hobson \& C. S. Stewart (Eds.), The rumen microbial ecosystem, 246-282. London, UK: Blackie Academic \& Professional. 
Santiago-Juarez, B., Moraes, L. E., Appuhamy, J. A. D. R. N., Pellikaan, W. F., Casper, D. P., Tricarico, J., \& Kebreab, E. (2016). Prediction and evaluation of enteric methane emissions from lactating dairy cows using different levels of covariate information. Animal Production Science, 56, 557-564. https://doi.org/10.1071/AN15496

Smith, N. E., \& Baldwin, R. L. (1974). Effects of breed, pregnancy, and lactation on weight of organs and tissues in dairy cattle. Journal of Dairy Science, 47, 1055-1060. https://doi.org/10.3168/jds.S00220302(74)85008-3

Tubiello, F. N., Salvatore, M., Rossi, S., Ferreira, A., Fitton, N., \& Smith, P. (2013). The FAOSTAT database of greenhouse gas emissions from agriculture. Environmental Research Letters, 8, 015009. https://doi. org/10.1088/1748-9326/8/1/015009

Tyrrell, H. F., \& Reid, J. T. (1965). Prediction of the energy value of cow's milk. Journal of Dairy Science, 48, 1215-1223. https://doi.org/10. 3168/jds.S0022-0302(65)88430-2

Van Nevel, C. J., \& Demeyer, D. I. (1996). Control of rumen methanogenesis. Environmental Monitoring and Assessment, 42, 73-97. https://doi. org/10.1007/BF00394043

Van Soest, P. J. (1994). Nutritional ecology of the ruminant. Ithaca, NY: Cornell University Press.

Vazquez, O. P., \& Smith, T. R. (2000). Factors affecting pasture intake and total dry matter intake in grazing dairy cows. Journal of Dairy Science, 83, 2301-2309. https://doi.org/10.3168/jds.S0022-0302(00) 75117-4

Warner, D., Bannink, A., Hatew, B., van Laar, H., \& Dijkstra, J. (2017). Effects of grass silage quality and level of feed intake on enteric methane production in lactating dairy cows. Journal of Animal Science, 95, 3687-3700.

Warner, D., Hatew, B., Podesta, S. C., Klop, G., van Gastelen, S., van Laar, H., ... Bannink, A. (2016). Effects of nitrogen fertilisation rate and maturity of grass silage on methane emission by lactating dairy cows. Animal, 10, 34 43. https://doi.org/10.1017/S1751731115001640

Zwillinger, D., \& Kokoska, S. (2000). CRC standard probability and statistics tables and formulae. Boca Raton, FL: CRC Press.

\section{SUPPORTING INFORMATION}

Additional Supporting Information may be found online in the supporting information tab for this article.

How to cite this article: Niu M, Kebreab E, Hristov AN, et al. Prediction of enteric methane production, yield, and intensity in dairy cattle using an intercontinental database. Glob Change Biol. 2018;24:3368-3389. https://doi.org/10.1111/gcb.14094 